\title{
Design for reduced resource consumption during the use phase of products
}

\author{
L.H. Shu (1)a, Joost Duflou (1) ${ }^{b}$, Christoph Herrmann (2)c, Tomohiko Sakao (2)d, Yoshiki Shimomura (1)e, \\ Yannick De Bock ${ }^{\mathrm{b}}$, Jayesh Srivastava ${ }^{\mathrm{a}}$ \\ ${ }^{a}$ Department of Mechanical and Industrial Engineering, University of Toronto, Toronto, Canada \\ ${ }^{b}$ Mechanical Engineering Department, Katholieke Universiteit Leuven, Leuven, Belgium \\ c Institute of Machine Tools and Production Technology, Technische Universität Braunschweig, Braunschweig, Germany \\ ${ }^{d}$ Division of Environmental Technology and Management at the Department of Management and Engineering, Linköping University, Linköping, Sweden \\ e Faculty of System Design and Graduate School of System Design, Tokyo Metropolitan University, Tokyo
}

Much work on sustainable design has focused on product manufacture/assembly and end of life. Gains in products' technical efficiency address the use phase, but how these products are used clearly affects resource consumption. There are two main approaches to design interventions to reduce resource consumption during product life. Firstly, interventions aim to change user behavior, through information and feedback, as well as physical product affordances abstracted from lead users to guide or steer users toward the desired behavior. Secondly, automatic adjustment of product systems performance levels based on personal user profiles and anticipated usage is implemented using artificial intelligence techniques.

Keywords: Sustainable development, Human aspect, Pro-environmental behavior

\section{Introduction}

The ambition to minimize products' environmental impact by proper decision-making during design has become known as eco-design or, when considering design in a broader perspective, as life-cycle engineering (LCE). In principle, LCE focuses on the full life-cycle of products: from business-model conception, over functional and technical product specification, product manufacture, distribution and use phase, until end-oflife, possibly taking into account lifetime extending strategies such as maintenance, repair, refurbishment and remanufacturing. Without targeting exhaustiveness, the below overview of reported results provides insights on strategies most commonly chosen to achieve the impact reduction envisaged in LCE.

\subsection{Business / manufacturing paradigms for LCE support}

A series of review papers have been compiled by optimization-oriented researchers. Westkaemper et al. (2000) listed approaches for Life Cycle Management, including Life Cycle Assessment, Product Data Management, Technical Support and Life Cycle Costing [229]. In response to globalization, Ueda et al. (2009) discussed decision making with respect to artifacts, social dilemmas, network externalities, and sustainability, towards service and production for sustainable value creation [220]. The growing attention on Product Service System business models as a paradigm involving manufacturers, with optimization opportunities over the entire product life cycle, was summarized by Meier et al. (2010) [144].

Contributions in this category tend to focus on manufacturers' perspectives when considering sustainability aspects of product manufacture and consumption, with emphasis on producer responsibility. This attention has been extended into the social dimension of sustainability. For example, Sutherland et al. (2016) explored the effects of manufacturing and globalization challenges on the social needs of different groups, with emphasis on worker well-being [206]. In addition to the socially-relevant work already summarized by Sutherland et al., Kondoh et al. (2011) proposed a method to include a wide variety of societal causalities into a cause-effect pattern library to support the design and planning of sustainable business ideas and activities [116].

\subsection{Design tools for LCE support}

Hauschild et al. (1999) have long recognized the effect of design on environmental performance and sustainable industrial culture [96]. However, Hauschild et al. (2004) noted that simply applying Design for Environment (DFE) does not always result in environmentally optimized solutions, but rather localized optimization specific to the DFE tools selected. Instead, a hierarchy of "refocusing" asks the designer to consider, how else the intended function may be provided, which product should be produced, and what are corresponding environmental challenges, before selecting a DFE tool that best addresses these challenges [97]. Kara et al. (2008) argued that to enable sustainable manufacturing, an optimum useful lifetime for products should be established early in the design process. Based on product failure mechanisms and corresponding lifetime prediction, the product's components should then be designed to require correspondingly minimal resource usage and environmental impact [108]. Hauschild et al. (2005) described the state of Life Cycle Assessment (LCA), and provided an overview of Design for Environment (DFE). Tools used to support DFE were discussed, with a focus on tools for design for disassembly. The authors also identified the need for stronger legislation, as well as education and attitude building among future citizens and engineers [98].

\subsection{Manufacturing to reduce use-phase consumption}

Researchers have also revealed the relevance of manufacturing-process choices for product performance and corresponding benefits during the use phase of the product life cycle. For example, Dornfeld (2014) demonstrated how the 
surface quality achieved by a manufacturing process determines the energy efficiency of automotive gear trains [58]. Chandra et al. (2014) discussed the role of surfaces and interfaces that critically influence the characteristics that determine solar-cell effectiveness. Also assessed were modifications to the surface interface to realize efficiency enhancement and cost and energy footprint reduction in solarcell manufacturing [33].

\subsection{Motivation for current work}

The above non-exhaustive domain scan supports that resource scarcity and the harmful environmental effects of industrial development have motivated a substantial amount of research. Much of this effort has focused on developing more resource-efficient manufacturing, from both product and manufacturing-system perspectives. However, the way in which products are used over their functional lifetime is rarely addressed. This is despite the use phase of the product life cycle being highly relevant for potential resource conservation in many product categories. Design optimization efforts typically target the static performance of products, while how products can influence their utilization by end-users during the use phase has received considerably less attention. In addition, Herring (2006) notes that improved energy efficiency lowers the implicit price of energy, making its use more affordable, leading to the rebound effect [24], and that "ultimately what is needed to limit energy consumption is energy sufficiency (or conservation) rather than energy efficiency" [101]. That is, resource-efficient devices may be used longer and remain left on unnecessarily more so than their less-efficient predecessors. Such behavior offsets at least part of the anticipated gains in resource efficiency intended by product-embedded resourcesaving modes and technologies. Therefore, in addition to creating technically efficient products, designers should also develop products that encourage and enable users to behave in more resource-efficient ways, which is the principal focus of the current paper.

\subsection{Paper overview}

There are many frameworks that are useful in considering how to design products to increase environmentally conscious or sustainable behavior by consumers. Product-design researchers, Zachrisson \& Boks (2010) and Bhamra et al. (2011) discuss the range of interventions for sustainable behavior in terms of user versus product control of the desired behavior [242][25]. At the informing end of the spectrum, information and feedback allow the user to be in full control. At the determining end, forcing and automatic performance of desired actions give control to the product. The persuading middle of the spectrum involves an interaction between product and user, and includes enabling, encouraging, guiding, and steering [242]. Lilley et al. (2005) use the terms: eco-feedback, scripting and behavioral steering, and 'intelligent' products and services [129]. Lockton et al. (2008) categorize interventions as feedback and persuasion, versus affordances, constraints and mistake proofing. Context-based approaches combine the two categories. The cognitive workload required is believed proportional to the amount of user control [132]. Figure 1 shows various terminologies for interventions along the spectrum of user versus product control.

The problems and theoretical background differ widely between the approaches that aim to 1) persuade a human toward a particular desired behavior, and 2) automatically perform the desired behavior for the human. Therefore, the paper is arranged according to these two main approaches as follows. Section 2 addresses design for behavior change, starting with models of human behavior and antecedents of behavior in Section 2.1. The various, growing sources of information relevant to design for behavior change cover a rather wide range of disparate domains. Therefore, Section 2.2 summarizes a possible framework in the form of a behaviorchange ontology to systematically organize this information. The importance of context for information and feedback approaches is discussed in Section 2.3. Affordance-based approaches and definitions of affordance are introduced in Section 2.4, and Section 2.5 outlines a design tool intended to address different user motivations. Section 3 introduces the automation approach and underlying artificial intelligence techniques. A case study that includes both information and automation approaches is given in Section 4, and Section 5 provides an outlook for future work in the field.

\section{Approaches that aim to change user behavior}

There is an enormous body of literature on changing human behavior, and specifically on facilitating pro-environmental behavior. Two of the most informative review papers by social psychologists are Abrahamse et al.'s (2005) "A review of intervention studies aimed at household energy conservation" [2] and Steg \& Vlek's (2009) "Encouraging Pro-Environmental Behavior: An integrative Review and Research Agenda" [202].

Abrahamse et al. categorized energy-conservation strategies as antecedent vs. consequence. Antecedent strategies target factors that precede behavior and include increasing problem awareness, giving information about options, enabling commitment and goal setting. Consequence strategies aim to change consequences after behavior, and include providing feedback, rewards or penalties [2]. Steg \& Vlek also distinguish between informational vs. structural strategies. Informational strategies are defined as "being aimed at changing perceptions, motivations, knowledge, and norms, without actually changing the external context in which choices are made". Such strategies were found to be effective when the desired behavior does not significantly inconvenience, cost, or constrain individuals, e.g., using signage to ask people to turn off lights [205]. Structural strategies include availability of products and services, legal regulation, and financial strategies. Such strategies aim to change the circumstances, e.g. costs and benefits, under which behavioral choices are being made, and were found to be more suitable when the desired behaviors are costly or difficult. The two types of strategies can be used in combination, e.g., informing people about the need for and consequence of structural strategies may increase public support for them [202]. Abrahamse et al. noted the limitations of interventions aimed to encourage energy conservation. In particular, information may lead to higher knowledge levels, but not necessarily to behavioral changes or energy savings [2]. Kollmuss \& Agyeman (2002) and others have also recognized that environmental awareness and knowledge do not necessarily lead to corresponding behavior [115]. Rewards have effectively encouraged energy conservation, but with short-lived effects corresponding to reward availability. Feedback has shown merits, especially when provided frequently. However, conclusions were limited by methodological problems in the studies describing the interventions. It was also often unclear whether the effects were maintained over longer periods of time [2]. The persistent barriers to sustainable behavior highlight the importance of better understanding existing work and charting new work towards improved interventions for sustainability. 


\begin{tabular}{|l|l|l|c|}
\hline Authors & \& User in control (high cognitive load) & Product in control (low cognitive load) $\rightarrow$ \\
\hline $\begin{array}{l}\text { Zachrisson \& Boks (2010) } \\
\text { [242] }\end{array}$ & Informing & Persuading & Determining \\
\cline { 2 - 4 } & Information, Feedback & Enabling, Encouraging, Guiding, Steering & Forcing, Automatic \\
\hline Lilley et al. (2005) [129] & Eco-feedback & Scripting and behavioral steering & Intelligent products \\
\hline Lockton et al. (2008) [132] & \multicolumn{2}{|c|}{ Context-based = Feedback \& persuasion +Affordances, constraints, mistake-proofing } \\
\hline
\end{tabular}

Figure 1: Intervention terminology of various researchers with respect to user versus product control.

\subsection{Models of human behavior}

Since design that aims to change behavior necessarily draws from diverse fields outside of engineering design, relevant concepts are first reviewed. Table 1 summarizes general behavioral models adapted from Srivastava (2016) [192].

Psychologists developed models of human behavior that aim to identify factors that affect behavior and to explain the processes of behavior change. One model, Bandura's (1986) Social Cognitive Theory, describes behavior as one of three interlocking determinants along with personal factors and environmental influences [17]. The most difficult of the three to understand are personal factors, which are represented in many different ways. One approach is to differentiate users by the values they hold, e.g., applying Schwartz's (1992) Universals in the content and structures of values [181]. A significant amount of behavior literature is based on Ajzen's (1991) Theory of Planned Behavior, which states that the following three factors together affect behavior: an individual's attitudes; subjective norms; and the amount of perceived control the individual has over the target behavior [3]. Summarized, attitudes refer to the individual's positive or negative appraisal of the behavior. Subjective norms refer to perceived social pressure regarding appropriate behavior. Also known as self-efficacy [16], perceived behavior control refer to how individuals perceive their abilities to perform given behaviors.

The above theories are intended to describe and affect behavior in general. Some researchers applied these theories to sustainability-related behavior. For example, Bamberg \& Schmidt (2003) compared the ability of the Ajzen, Triandis, and Schwartz models to predict car use in university students [14].

Table 1: Summary of selected general models of behavior (adapted from [192])

\begin{tabular}{|c|c|c|}
\hline Model & Authors & Summary \\
\hline $\begin{array}{l}\text { Self- } \\
\text { Efficacy } \\
\text { Theory }\end{array}$ & $\begin{array}{l}\text { Bandura } \\
(1977) \\
{[16]}\end{array}$ & $\begin{array}{l}\text { Self efficacy refers to individuals' confidence in their ability to perform an action, and has } 3 \text { dimensions: } \\
\text { 1. Strength: strong vs. weak self-efficacy } \\
\text { 2. Generality: self-efficacy across many situations vs. in only some situations } \\
\text { 3. Level/Difficulty: self-efficacy in only easy tasks vs. in even difficult tasks }\end{array}$ \\
\hline \begin{tabular}{|l|} 
Norm \\
Activation \\
Model
\end{tabular} & $\begin{array}{l}\text { Schwartz } \\
(1977) \\
{[180]}\end{array}$ & $\begin{array}{l}\text { Personal Norms refer to feelings of moral obligation that guide behavior, and are determined by } 2 \text { factors: } \\
\text { 1. Awareness of a behavior's negative consequences } \\
\text { 2. Feeling responsibility for negative consequences of one's behavior }\end{array}$ \\
\hline \begin{tabular}{l|} 
Theory of \\
Inter- \\
personal \\
Behavior
\end{tabular} & $\begin{array}{l}\text { Triandis } \\
(1977) \\
{[216]}\end{array}$ & $\begin{array}{l}\text { Behavior has } 3 \text { main antecedents: } \\
\text { 1. Intention, which has } 5 \text { determinants: } \\
\text { 1.1. Self Identity } \\
\text { 1.2. Personal Normative Beliefs (How the user thinks he/she is expected to behave) } \\
\text { 1.3. Perceived Social Norms (Role Beliefs / Normative Beliefs) } \\
\text { 1.4. Perceived Consequences } \\
\text { 1.5. Affect (emotions and emotional state) } \\
\text { 2. Habit (behavioral frequency) } \\
\text { 3. Facilitating conditions (external factors) }\end{array}$ \\
\hline \begin{tabular}{|l|} 
Social \\
Cognitive \\
Theory of \\
Behavior
\end{tabular} & $\begin{array}{l}\text { Bandura } \\
(1986) \\
{[17]}\end{array}$ & $\begin{array}{l}\text { Triadic Reciprocal Determinism: The following three components are interlocking determinants of each other. } \\
\text { 1. Behavior (actions) } \\
\text { 2. Personal factors (expectations, beliefs, self-perceptions, goals, intentions, sensory abilities, individual physical structure, } \\
\text { emotional state) } \\
\text { 3. Environmental influences (situations) }\end{array}$ \\
\hline \begin{tabular}{l|} 
Theory of \\
Planned \\
Behavior
\end{tabular} & $\begin{array}{l}\text { Ajzen } \\
(1991) \\
{[3]}\end{array}$ & $\begin{array}{l}\text { Behavior is a result of intention to act, which depends on } 3 \text { determinants: } \\
\text { 1. Attitude toward behavior (individual's favorable versus unfavorable appraisal of behavior) } \\
\text { 2. Subjective norm (perceived social pressure to perform or not perform behavior) } \\
\text { 3. Perceived behavioral control (perceived ease or difficulty of performing behavior) }\end{array}$ \\
\hline
\end{tabular}

Other researchers developed theories specific to sustainabilityrelated behavior. For example, Stern et al. (1999) extended Schwartz's Norm Activation Model and developed the ValueBelief-Norm theory to describe environmentally significant behavior. This theory states that values, beliefs and norms lead to attitudes, which lead to behavior, and that problem awareness depends on values and worldviews [203]. Stern's (2000) framework categorized people's behavior that affects the material and energy flows of the environment as: active vs. passive, intentional vs. unintentional, and public vs. private [204]. Shove \& Warde (1998) noted that, although the consumption of utilities, e.g., electricity and water, is a private matter, the trend toward higher consumption rates makes related behaviors increasingly relevant [187]. The terms pro-environmental, environmentally significant, environmentally conscious, and sustainable behavior are used by different researchers. This paper will use the most commonly occurring term, Pro-Environmental Behavior or PEB. Table 2 summarizes select PEB models, adapted from [192].

\subsubsection{Antecedents of behavior}

Srivastava identified antecedents of behavior that recur in many different PEB models [192]. Some of these antecedents are regrouped into five categories as shown in Fig. 2, ranging from those that are more internal to a person (e.g., values) to those that are more external (e.g., physical environment). While engineers are likely more accustomed to affecting the latter, external antecedents, understanding the former, more internal antecedents may enable more coherent interventions for PEB. Steg \& Vlek note that interventions are more effective when they address antecedents of behavior as well as removing barriers for change. In addition, different antecedents should be addressed in different situations. For example, Stern's value-belief-norm theory on PEB may be more effective at explaining low-cost environmental 
behavior such as policy acceptance. However, situations with high behavioral costs or constraints, e.g., reducing car use, may be better explained by Ajzen's Theory of Planned Behavior that includes non-environmental motivations and perceived control over relevant behavior [202].

\section{Individual values, beliefs, and attitudes}

The importance of values, beliefs, and attitudes dominates PEB models. Therefore, their definitions are first discussed.

Schwartz (1992) described values as general goals that transcend situations, e.g., honesty tends to be consistent between personal and professional situations. Values also act as standards or criteria, whose role in decision making may be unconscious unless conflicts occur between different values. Schwartz explains that human values can be categorized along two dimensions. The first dimension describes a person's level of selfishness between self-enhancement and self-transcendence. Examples of values that serve individual interests include hedonism, achievement and power. Values that serve primarily collective interests are benevolence and universalism. The second dimension describes a person's values with respect to conservation (conformity/tradition and security) versus openness to change (stimulation and self-direction) [181].

Attitudes are described by Schwartz (2012) as evaluations on a positive versus negative scale, e.g., good or bad, desirable or undesirable. Values form the basis for these evaluations, i.e., objects consistent with valued goals are evaluated positively and vice versa [182]. For example, those who have values consistent with environmental protection are more likely to have a positive attitude towards resource conservation.

Beliefs are described by Schwartz as "ideas about how true it is that things are related in particular ways," varying in one's certainty that they are true, and with respect to behavior, an evaluation of likelihood that behavior has particular consequences. Many statements of beliefs can be found in Dunlap and Van Liere's (1978) New Environmental Paradigm (NEP), an instrument intended to measure one's ecological worldview, which reflects general beliefs on the human-nature relationship. For example, members of the general public versus an environmental organization were very different in their agreement for the statement, "Mankind is severely abusing the environment" [61]. Schwartz further states, "Unlike values, beliefs refer to the subjective probability that a relationship is true, not to the importance of goals as guiding principles in life" [182]. Table 2 confirms the role of values, beliefs, and attitudes in many PEB models.

\section{Expectations of behavior: Personal and Social Norms}

Norms refer to internalized expectations about behavior. Personal norms refer to self expectations, often conceptualized as feelings of moral obligations. Thøgersen (2009) and Doran \& Larsen (2016) developed models specific to PEB, and describe personal norms as expectations of one's own behavior based on reasoning or past experience [209][56]. Social norms refer to perceptions of expectations of others, and may be experienced as social pressure. In discussing public littering, Cialdini et al. (1990) distinguished between injunctive norms as perceptions about what most others approve or disapprove, and descriptive norms as perceptions about what most others do [39].

As shown in Table 1, several general behavioral models identify personal and social norms as significant motivators of behavior. Schwartz's Norm Activation Theory (1977) identified personal norms as the main guide of behavior. Personal norms are determined by awareness of negative consequences of a behavior and feeling responsible for negative consequences of one's behavior [180]. Triandis' Theory of Interpersonal Behavior (1977) included personal and social norms as determinants of intention, which is one of three behavioral antecedents [216]. Bandura's Social Cognitive Theory of Behavior (1986) accounted for expectations under personal factors, one of three interlocking determinants of behavior [17]. Ajzen's Theory of Planned Behavior (1991) described behavior as resulting from three determinants of intentions, one of which is subjective norms [3].

As shown in Table 2, several PEB models identify personal and social norms as antecedents of sustainability-related behavior. Hirose's two-phase model of PEB (1994) described personal norm as an assumption of personal responsibility to act in the first phase, followed by the intention to comply with social norms in the second phase [102]. Ölander \& Thøgersen (1995) included social norms under motivation [164]. Stern identified personal norms as one of four PEB determinants [204]. Kollmuss \& Agyeman account for social norms under external factors [115]. Steg \& Vlek listed personal norms under morals and normative concerns [202]. Klöckner \& Blöbaum (2010) identify normative processes as indirectly influencing behavior [111]. Kurisu (2015) lists norms (including personal and social norms) as the first of ten factors in either encouraging or hindering PEB [121].

\section{Habits and behavioral patterns}

Table 2 also shows how several PEB models account for the role of habits. For example, Kollmuss \& Agyeman acknowledge that existing behavior patterns may hamper adoption of new, more sustainable behaviors.

Tversky \& Kahneman (1974) describe heuristics and cognitive biases as automatic mental shortcuts people often use to make decisions without expending much cognitive effort [219]. Triandis' Theory of Interpersonal Behavior (1977) identifies as one of the main antecedents of behavior the closeness of a desired behavior to a person's existing habits [216].

Thaler \& Sunstein's Nudge model (2008) divides human decision making into two systems: System 1 is impulsive and spontaneous; and System 2 is deliberative and mindful [208]. A possible benefit of turning a desired PEB into habit is that it exploits the spontaneous nature of System 1, rather than relying on the effortful nature of System 2. Fujii \& Gärling (2003) reported that frequent drivers who changed to public transit during an 8-day road closure continued to use public transit more often a year after the closure than the drivers who did not use public transit in the closure [78]. This study is often cited to support that habits can be broken, if people try new behavior and learn that the new behavior has more positive consequences than they anticipated. Davoudi et al. (2014) investigated rational versus habitual aspects of energy consumption behavior. They prioritized the forming of new habits consistent with PEB, as this may elevate related behaviors from practical or routine to "discursive (intentional, goal-oriented) consciousness" at the community rather than individual level [49].

\section{Individual perceptions of own abilities}

Bandura's Self-Efficacy Theory asserts that people have very different levels of self-efficacy. That is, people's confidence in their ability to perform an action vary greatly at different times and situations and because of innate differences [16]. This self-efficacy level determines peoples' likelihood of performing specific actions. Ajzen's Theory of Planned Behavior refers to a similar concept as perceived behavioral control, or a person's perceived ease or difficulty in performing a behavior. Higher perceived behavioral control increases the likelihood the behavior is performed [3]. Bandura's Social Cognitive Theory of Behavior includes selfperceptions under personal factors, which comprise one of the three main antecedents of behavior [17].

Not included in the general models of Table 1 are the following. Deci \& Ryan's Self Determination Theory (2000) attributes a person's motivation for performing behaviors to three personal factors: 1) feeling of autonomy in a situation (the amount of 
Fig. 2: Antecedents of behavior: From Values to Circumstances

\begin{tabular}{|ccccc|}
\hline$\leftarrow$ More internal & & & \\
\hline $\begin{array}{c}\text { 1. Values } \\
\text { Beliefs, }\end{array}$ & 2. Expectations & Personal / & Sabits & More external $\rightarrow$ \\
attitudes, & social norms & Heuristics, & Awareness, knowledge, feasibility, & 5. Circumstances \\
intentions & & Associations & confidence, ease & Context, Situation, Opportunity, \\
Costs/benefits, incentives, constraints, \\
Conditions: available products/facilities
\end{tabular}

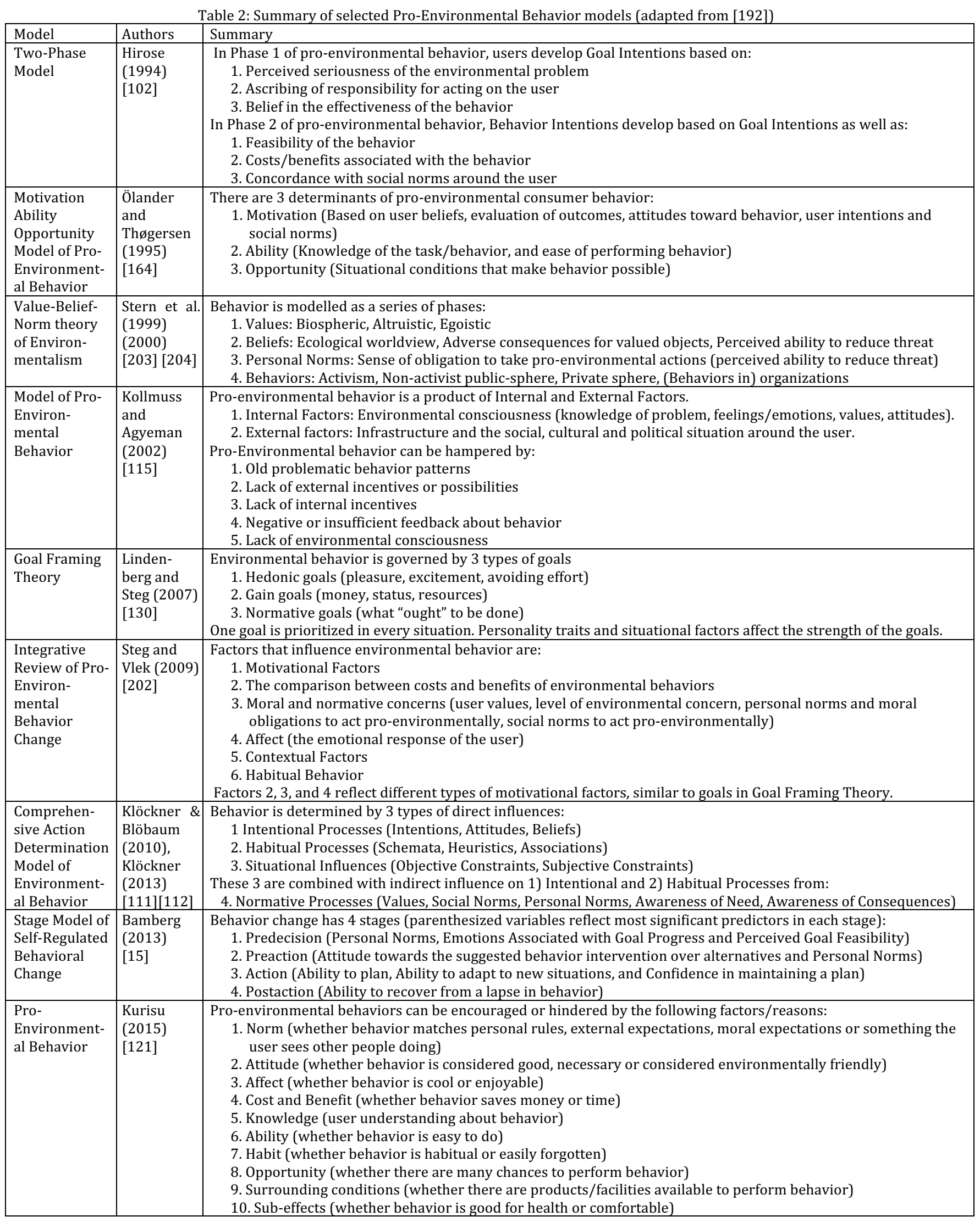


perceived independence), 2) feeling of relatedness to others in the situation and 3) assessment of own competence (i.e., self-efficacy) [54]. Rosenstock et al.'s Health Belief Model (1988) listed perceived self-efficacy as one of the six factors that determine prohealth behavior [176]. Csikszentmihalyi et al.'s Flow theory (1988) states that behaviors with ease-of-action (i.e. how well they map to the person's abilities) become attractive to people [45].

Although not identified in as many PEB models, there is potential value from a design perspective to separate individual perceptions of own abilities from the final category of external factors. Specific to PEB, Stern listed under beliefs, the perceived ability to reduce threat. Stern's conceptualization of efficacy is different from self efficacy, but rather reflects outcome efficacy. That is, it is not perception of whether one is capable of engaging in a PEB, but perception that one's efforts/behavior would be effective in reducing (environmental) problems [204]. Bamberg listed under action, the abilities to plan, adapt and confidence [15]; and Kurisu used ability to describe whether a behavior is easy to do [121].

\section{Circumstances: External/Situational/Contextual Factors}

Finally, the external characteristics of a situation refer to context, situation, opportunity, costs/benefits, incentives, constraints, conditions, available products and/or facilities. Liu \& Sibley (2004) note that structural interventions, i.e., adding ashtrays and litter bins, reduced cigarette littering by $64 \%$, without changing attitudes towards littering [131]. Gardner \& Stern (2008) provide a short list of the most effective actions U.S. households can take to curb climate change [80]. Efficiency behaviors are described as replacing less efficient with more efficient products, e.g., buying a more fuel-efficient home heater. Curtailment behaviors involve using existing products more efficiently, e.g., reducing temperature on heater. While efficiency behaviors may be more impactful and require less cognitive effort than curtailment behaviors, efficiency behaviors are hindered by a myriad of obstacles. Such obstacles include financial expense, but also end users, e.g., renters, may have little control over the choice of appliances. Even those with both control and financial means, incentives like rebates are hampered by the logistical challenges of identifying suitable equipment and arranging the various trades needed to install such equipment [80]. Such obstacles fall under external factors. Tables 1 and 2 show that both general and PEBspecific models make references to such factors under a variety of names, e.g., facilitating conditions, environmental influences, contextual factors, situational influences, and external factors.

\section{Other factors}

Although the PEB models summarized are by no means exhaustive, the aspects some mention that do not fall under the above categories are worth noting. These include: Hirose's perceived seriousness of the environmental problem (related to adverse consequences in Value Belief Norm theory); Lindenberg \& Steg's (2007) hedonic goals of pleasure and excitement; Bamberg's postaction, or ability to recover from a lapse in behavior; Kurisu's sub-effects, or whether the desired PEB is also good for health or comfort, and can be considered as beliefs that predict attitudes.

Finally, Steg \& Vlek identified affect, or the user's emotional response, as a separate factor that influences PEB [202]. Triandis' Theory of Interpersonal Behavior ascribes a person's intention to perform a behavior to the individual's affect or emotional state [216]. Steg (2005) confirms the importance of symbolic and affective motives, in addition to instrumental (functional) motives in car use [199]. Bratt et al. (2015) discuss yet other ways of structuring PEB [27].

\subsubsection{Conclusions on antecedents of behavior}

Returning to the topic of interventions, Abrahamse et al. noted that rewards were more effective than penalties in encouraging
PEB, but they tend to have short-lasting effects, i.e., only as long as the reward is available [2]. Evans et al. (2013) point out that information campaigns which emphasize self-interested, e.g., economic, reasons may fail to cause spillover, or an increase in other, different environmental behaviors [68].

Social scientists such as Steg et al. (2014) are suggesting a return to values, rather than extrinsic rewards, in framing messages to motivate sustainable behavior [200]. Specifically, appeals that focus on financial incentives may convince people to perform the targeted sustainable behavior, but such people are less likely to continue in the behavior, or engage in other sustainable behavior than if the appeal focused on values, i.e., "This is the right thing to do." However, potential rebound effects must be considered [24], both first-order (see Section 3.4.2) and second-order, where incentives may lead to higher incomes and additional consumption in other areas.

While many social psychologists continue to work on message framing for PEB, how does an engineering designer change the values of consumers? The current paper proposes that one approach is by addressing antecedents, numbered 1 to 5 , from the right of Figure 2, moving incrementally leftwards. That is, by changing external circumstances to support PEB (5), consumers will then change their individual perceptions of their abilities to perform PEB (4), and thus habits and behavior patterns (3), thereby changing their expectations of self and others' behavior (2), which then changes at least attitudes, if not also beliefs and then values (1). In addition, efforts on each antecedent from external to internal will likely produce insights on how to more directly affect the next internal antecedent. That is, while designing to change people's external circumstances, one may also learn how to design to change their perceptions of their abilities directly.

\subsubsection{Using models to change behavior}

In addition to the preceding models, other general models focus on the process of behavior change. For example, Prochaska \& DiClemente's Transtheoretical Model (1984) identifies the five stages of behavior change as: pre-contemplation, contemplation, preparation, action, and maintenance [173]. While the aforementioned Bandura's Social Cognitive Theory [17] and Ajzen's Theory of Planned Behavior [3] aim to explain the what of behavior change, the Transtheoretical Model aims to understand the how or when. Janz \& Becker (1984) reviews how the Health-Belief Model, which incorporates the Transtheoretical Model, is applied to disease prevention, including exercising and weight loss, overcoming alcohol/drug/tobacco addiction, and using safety equipment [107]. Klein et al. (2011) identifies the Health-Belief Model's six determinants of behavior related to perception as: susceptibility, severity, benefits, barriers, motivation and cues for action [110]. As mentioned, Thaler \& Sunstein used nudges, or small reminders to target people's cognitive biases towards desired behavior [208]. Specific to PEB, Bamberg applied the stage model of self-regulated behavior change to car-use reduction [15].

In the field of product design for behavior change, Lockton et al.'s (2010) Design with Intent framework defines seven categories of behavior patterns, called lenses, that correspond to how products influence user behavior [133]. Examples provided under each lens may be used for inspiration.

As the basis of persuasive technologies, Fogg (2003) identifies strategies including: simplifying or guiding through a procedure, tailoring and individual customization; conditioning and reinforcement; opportune suggestion and intervention; and selfmonitoring vs. allowing others to track users' behavior [73]. The Fogg Behavior Model (2009) also decomposes user behavior into different types, e.g., doing a familiar behavior once, stopping a behavior for a period of time, and starting/continuing a new behavior. The designer is then advised on how to effect behavior change for each type [74]. However, Brynjarsdottir et al. (2012) 
critically reviewed work on persuasive sustainability, i.e., those that claim to apply Fogg's Model to PEB as overly focused on information and feedback [29]. Coskun et al. (2015) also noted the overemphasis on information and feedback, and support turning desired behaviors into habits [43].

\subsubsection{Challenges in applying behavior-change literature}

As described above, much behavior-change research has been performed by non-engineers, and may thus be less known to engineering researchers. In addition, the different aims, terminology and conventions make such research more difficult to unify and analyze. Regarding the aims of researchers from different disciplines, psychologists and behavioral economists interested in the rational and emotional motivations that lead to behavior, tend to postulate descriptive models of how behavior change occurs [150]. In contrast, some design researchers perform case studies of behavior-change interventions and inductively identify design principles towards behavior change [242][232][133][193][194][195]. Other design researchers fit between these approaches, aiming to find principles for change while creating models of behavior change. Such differing aims, approaches, and domain-specific terminology used to describe results, create obstacles in comparing and integrating findings from different groups of researchers. Insights arising from these studies are also presented such that they may be difficult for engineers and designers to apply. Behavior-change strategies or principles may provide direction in terms of where and how they should be applied. In contrast, behavior-change models do not usually prescribe strategies sufficiently specific for application. Thus, while containing useful insights for engineers, behaviorchange knowledge presents challenges for access and application.

\subsection{Behavior-Change Ontology (BCO)}

As a possible way to address the above challenges, Srivastava \& Shu (2014a) created an ontology to increase the accessibility of existing work on behavior change. This ontology serves as a knowledge framework to organize this body of literature, and better support its application towards design for behavior change, e.g., towards reduced resource consumption [195].

Semantic web technologies, e.g. ontologies, provide a useful way to clarify and organize the results of behavior-change research. Uschold \& Gruninger (1996) describe an ontology as a unifying framework that defines terms and the relationships between these terms using formal logic [222]. Ontologies have been used to store knowledge in many domains. These include design, e.g., user requirements during conceptual design [37], manufacturing and sustainability, e.g., knowledge for life-cycle management [57] [95], and combining functional and sustainability dimensions [198]. Ontologies are also well suited to uniting the concepts in behaviorchange research.

\subsubsection{Behavior-Change Ontology (BCO) classes and sources}

Constructed using a web ontology language, the Behavior-Change Ontology (BCO) categorizes information under the headings: Authors, Applications, Problem Type, Barriers, Principles, Strategies, and Mechanisms. A variety of sources were consulted to create the ontology, and each provided insights on different aspects of behavior change. Figure 3 shows a schematic of the main classes used to capture different facets of behavior change.

Authors refer to researchers who reported corresponding concepts, while applications contain examples showing where behavior-change concepts have been used, supporting designers who seek suggestions for a specific product or behavior domain. Although similar design solutions could be used for different behaviors, the examples under applications may provide specific ideas that are not available under the more abstract categories.

Problem type refers to the kind of behavior change targeted. Sources of insights include psychology and behavioral economics theories such as Prochaska \& DiClemente's Trans-Theoretical Behavior Model [173] and Fishbein \& Ajzen's (1975) Theory of Reasoned Action [71]. The seven levels of problem type include promoting a behavior that is completely new to a person, and for an existing behavior, levels range between needing to increase a behavior and stopping a behavior.

Barriers refer to obstacles that humans face in making behavior changes. Sources of insights include social-psychology studies, e.g., Abrahamse et al.'s review of energy-conservation interventions, and design studies that aim to capture human needs. Obstacles include lack of awareness, social restrictions, and limitations in time or economic terms. Behavior-change interventions also impose new barriers to effect new behaviors.

Principles refer to generalized approaches for changing behavior that researchers propose after reviewing intervention case studies. Design research related to behavior change extrapolated principles for behavior change, e.g., Zachrisson \& Boks refer to principles as strategy categories [242]. Principles capture information from many different examples and abstract them into a generic concept. This abstractness and generality also make them less effective as starting points for design, as they may lack details that guide designers towards solutions.

Strategies refer to the particular ways in which interventions are intended to affect behavior. Design research related to behavior change also presents strategies for modifying behavior. Compared with principles, strategies are stated more clearly, e.g., provide warnings if users deviate from desired actions. They are thus easier for designers to use for generating ideas. Lockton et al.'s Design-with-Intent framework refer to strategies as patterns, and provided 101 of the strategies in the BCO [133].

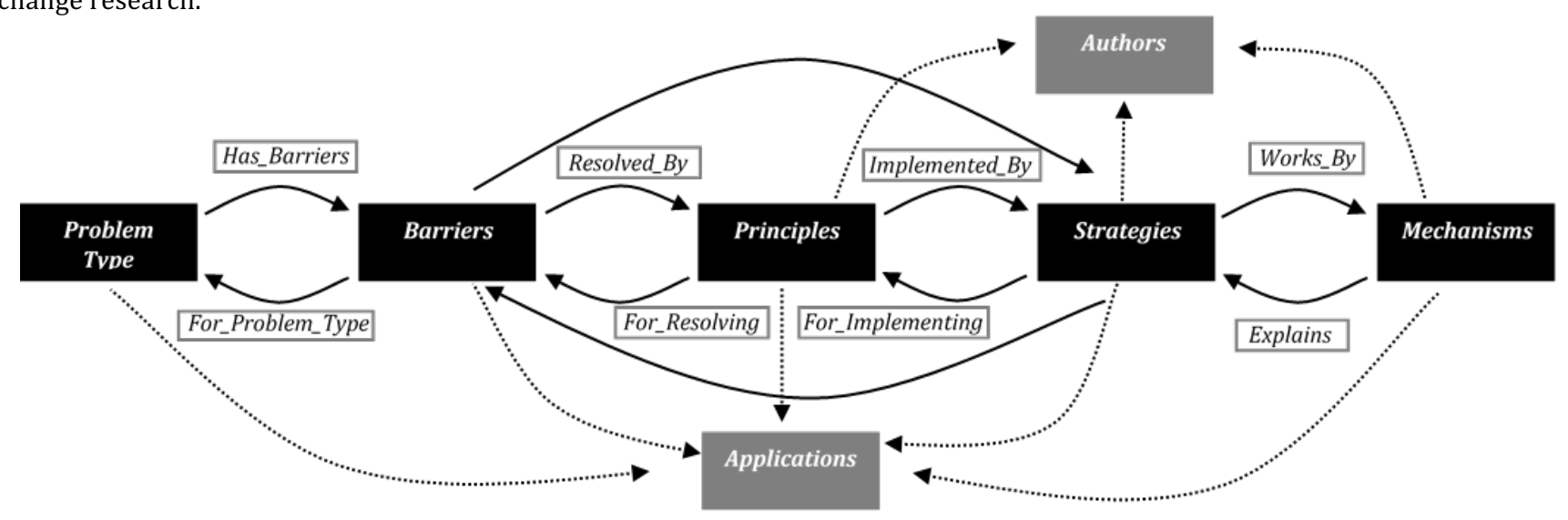

Figure 3. General schematic for Srivastava \& Shu's (2014a) Behavior-Change Ontology. (Get image permission) 


\subsubsection{Mechanisms for behavior change}

Of particular interest for practical use of the Behavior Change Ontology are Mechanisms, or postulated explanations for why specific strategies work to change behaviors. Sources include the uses by Janz \& Becker and Rosenstock et al. of the Health Belief Model [107] [176]. Design researchers, e.g., Fogg \& Hreha (2010), Lockton et al. and Daae \& Boks (2011) may also determine underlying mechanisms behind the strategies identified from case studies [75][133][46]. From such sources, six examples of mechanisms describe how strategies lead to behavior change.

\section{Obtrusiveness}

Many behavior-change strategies work by increasing or decreasing the obtrusiveness of a product feature. For example, the Are You Sure strategy, which suggests that a person must reconfirm a decision before executing the corresponding command, works by increasing the obtrusiveness of the decision feature [133]. In manufacturing, machines that require human operators to use both hands to turn them on to prevent injury, is an example of a highly obtrusive behavior-changing feature. Such strategies can help prevent errors and break habits.

\section{Operator Ability}

Behavior-change strategies also work by increasing or decreasing a person's ability to perform certain actions. For example, the Conveyor Belt strategy moves an object related to a behavior directly to a person, thereby increasing that person's ability to perform the behavior by reducing physical effort [133]. Fogg \& Hreha (2010) identify that changes in factors such as time available, money, physical effort, brain cycles and social pressure all affect a person's ability to perform desired behaviors. For PEB, recycling containers often have openings in shapes that correspond to the majority of objects intended for that opening, e.g., round holes for cylindrical bottles and cans. Thus, such strategies aim to remove barriers and provide opportunities.

\section{Comparison}

Behavior-change strategies also work by comparing an intended behavior with other options, e.g., the Framing strategy suggests presenting a desired behavior in attractive terms, often by presenting it alongside unattractive alternatives. PEB feedback often compares one's use of resources with others' (lower) uses. These three examples differ from a psychological point of view. Framing means emphasizing benefits in line with core values and can change attitudes. Comparing to unattractive alternatives may change attitudes (desired behavior looks relatively more effective). Normative feedback that compares own behavior or performance to that of others changes descriptive norms.

\section{Trigger}

Many behavior-change strategies use cues to prompt people to perform a desired behavior. These may work by triggering associations between a desired behavior with a person's alreadyroutine behavior. For example, medications may be taken at specific times of days, which may correspond to routine behavior such as eating meals; although no prompt is introduced, automatic association is established. As another example, a prompt, e.g., sticker to turn off light next to the switch, aims to remind people of their intention to do so, and breaks or forms a habit or routine.

\section{Motivation}

Behavior-change strategies often aim to increase a person's motivation for performing a behavior. For example, Fogg \& Hreha's (2010) Social Proof strategy shows a person examples of peers performing the desired behavior to promote it, and relates to descriptive norms. For PEB, some people may recycle because their neighbors recycle, and curbside recycling is a highly visible activity where sorted waste is left out, reflecting modelling through behavioral examples. A subsequent section further discusses sources of motivation.

\section{Control}

Many behavior-change strategies work by increasing or decreasing the amount of control the human has when performing a behavior. Lockton et al.'s (2010) Defaults strategy sets the designer-intended mode of use as the default setting, taking away some control from the user to encourage a particular behavior. For example, to reduce energy needed to heat water, the default faucet handle position could be set to deliver cold instead of warm water.

\subsubsection{Conclusions on the Behavior-Change Ontology}

The BCO presents a flexible and open structure that can be added to or changed by researchers as they collect additional relevant work. For example, Daae \& Boks (2014) propose nine dimensions of behavior change as: 1) Control: user vs. product; 2) Obtrusiveness: demand attention vs. stay unnoticed; 3) Encouragement: promote vs. discourage; 4) Meaning: fun vs. sensible; 5) Direction: desirable vs. undesirable to user; 6) Empathy: focus on user vs. on others; 7) Importance: users find it important vs. unimportant; 8) Timing: prompt users before vs. during vs. after behavior; 9) Exposure: frequent vs. rare intervention [47]. Gifford \& Nilsson's (2014) review identifies 18 personal and social factors that combine to influence PEB. They recognize that PEB may also be caused by motivations other than the 18 factors, such as saving money and improving health [87].

Many studies in the area of behavior-change research involve case studies, for which a standardized way of collecting and storing corresponding data facilitates comparison with other case studies. For example, Golan \& Fenko (2015) found that people's evaluation of the amount of running tap water is significantly affected by sound, suggesting possible benefits of amplifying this sound in redesigned water faucets, especially in public-use contexts, where less frequent use reduces acclimatization effects [88]. Linked to behavior determinants, adding sounds make people more aware of the behavior, and may increase the likelihood that they consider the consequences of their behavior. The effect of sound had already been used to increase awareness of the consumption of other resources, e.g., electricity. If researchers are supported in examining relationships and comparing properties between concepts, they may more quickly identify overlaps between findings, and identify new connections in transferring behaviorchange interventions between application areas.

\subsection{Role of context on information and feedback}

Social scientists continue to focus on the effect of information and feedback, e.g., Arpan et al. (2015) studied the interaction between message framing and values and norms in buildingoccupant responses to an energy-efficiency program. They found that personal norms "predicted willingness to dress differently, and perceptions that other occupants tried to conserve energy were related to increased intention to complain about the program" [8]. Bailey et al. (2015) reported that participants exposed to "vivid" messages used cooler water for hand washing than those not exposed to these messages [12].

In addition to other limitations of using information and feedback as interventions, such information only works if it is consistent with the goals of the user. For example, someone uninterested in resource conservation is unlikely to be affected by feedback concerning resource consumption. Furthermore, even if feedback works, there is a limit on how much information a person can absorb and heed. However, because information and feedback 
constitute simpler and likely less costly interventions than those based on affordances or automation, there is value in better understanding how it could be improved.

With respect to product design, one may consider context in two ways, context-based design, and design-of-context, when using information towards behavior change. Context-based design involves designing with existing context in mind. Design-ofcontext involves redesigning the use context, e.g., by providing information and feedback.

Benzoni \& Telenko (2016) review intervention studies aimed at domestic water conservation, and support the importance of context in the use of information and feedback as behavior-change interventions. Context is used to mean situational awareness, i.e., of consequences because of users' experiences. The authors discuss how generally ineffective information and tips on how or why to conserve water, successfully led to significant water savings when given in a drought context [23].

Consistent with General Design Theory [240], context is crucial to the effectiveness of interventions. Many interventions that provide or collect only information, targeted at customers, citizens, manufacturers, designers, etc. have failed. Such failures clarify the importance of mastering and sharing context to realize common understanding, e.g., in product design, service design, act for environmental load reduction, etc. As beliefs, ethos, culture and daily activities are all formed with context, to realize common understandings, context sometimes must be changed by both information sharing and consensus building.

The Japanese concept of $b a$ is a certain shared state for context sharing and rebuilding. The German concept of Aufheben also explains the above-mentioned context sharing/rebuilding process. Creating good ba has revealed itself as one of the most important issues for realizing good interventions. Yoshikawa (1981) used the term "field" to refer to ba to explain his function or design knowledge models in general design theory as, "The field is the circumstance which is effective for a function to manifest," and "Many different functions manifest on an entity according to fields" [240]. Tomiyama and Yoshikawa (1986) also use "field" to refer to ba as follows: "When the design solution is materialized, although it is exposed to the specified field, it might have behaviors different from the specifications. These behaviors are called unexpected functions" [212]. This definition relates and concepts of ba and affordances, detailed in the next section.

Furthermore, Nonaka et al. (2000) defined ba as "shared dynamic contexts", which has long been discussed in the Japanese business science field [160]. Many failures in manufacturing and supplying environmentally friendly products and services can be explained as sharing problems in context, ba or field. Case studies in Product-Service Systems (PSS) on supplying environmentally friendly micro-energy systems for developing countries report the existence of barriers on introducing such systems. Namely, Müller et al. (2009) found many differences between developing and developed countries' stakeholder customs, cultures, social rules, local conditions and specific circumstances. In some cases, misread and insufficiently understood context have led to failed introductions of environmental friendly systems [155].

Nemoto et al. (2015) present a context-based PSS design methodology as an approach for good ba creation for relating stakeholders [159]. Akaka \& Vargo (2015) also refer to the importance of ba and "context" in the service-marketing research area. They introduced the concept of servicescapes to have very limited meaning of physical, tangible service offerings, provideruser communication environment and space [4]. Servicescape can be interpreted as a limited form of ba, and service providers use servicescapes as communication channels to provide context information to their customers. An example of successful ba involves Digital Grid Corporation, through local kiosk businesses, replaced oil lamps with electric lanterns in Tanzania [1].

\subsection{Approach based on physical product affordance}

Many design researchers support user-centered design as a way to develop products that support PEB. For example, Wever et al. (2008) and Daae \& Boks (2015) review user-centered design methods, focusing on the social-psychology factors that affect behavior, towards creating solutions that favor sustainable behavior [230] [48]. Cor et al. (2014) present a protocol to perform usage-oriented eco-design that combines a task-realization analysis with a model of the entire use phase [40]. Elias et al. (2008) describe user-centered eco-design as designing for either current or new behaviors. For example, after narrowing down targets to those with both high-energy consumption and high user interaction, user observation revealed that the major use impact with a refrigerator is the amount of time that the door is open, which allows cold air to escape and warm air to enter. Noting that the time taken to remove items from the refrigerator is almost double the time to return items, improved concepts were proposed that would better present refrigerator contents so that items can be found faster or be seen without opening the door [64].

The concept of affordances provides a useful construct to design products that change behavior by examining how the user-product interaction takes place [161]. Affordances correspond to potential uses of an object [137]. Therefore, changing product affordances may modify the degree to which a user can perform a behavior. Bhamra et al. described eco-steer as design-oriented affordances and constraints that facilitate users in adopting more sustainable use habits through the prescriptions and constraints of use embedded in the product's design. An example involves detergent tablets that counter excessive detergent consumption by prescribing the correct dose [25].

\subsubsection{Definitions}

Shu et al. (2015) describe affordances as possible ways of interacting with products, which may be independent of designer intention [186]. This is consistent with Gibson (1977), who defined affordances as relational qualities that are functions of both user attributes and object attributes [85]. When users interact with a product, they perceive a set of affordances corresponding to the actions or uses they imagine they can perform with the product. Conversely, when designers develop a product, they intend certain uses, often defined as the functions of the product.

For example, any flat horizontal surface affords the placing of items on it. Such flat surfaces may be intended for such uses, e.g., bookshelves and tabletops are flat horizontal surfaces that exist for the function of supporting items. However, many such surfaces arise from other functions, but still afford the placing of items on top, which may not always be desirable. For example, flat horizontal surfaces often occur on top of enclosures that include ventilation grills, as with some dehumidifiers, heaters, etc. Items placed upon such flat surfaces may reduce ventilation or constitute fire hazards. To reduce possibility for this misuse, inclined slopes on top of such products removes this flat-surface affordance. On the other hand, product geometry that arbitrarily prevents the resting of objects on top, e.g., for aesthetic reasons, may unnecessarily thwart a commonly experienced need.

Ideally, agreement between a product's intended and perceived use is better managed, i.e., users only perceive those product uses that are desirable or possible. In addition to the potential misuse of products just described, user frustration can arise when users perceive actions that are not possible with the product.

Other researchers focus on different aspects of affordances. For example, Gaver (1991) identified characteristics of product affordances with respect to perceptual information as perceptible (discernable), hidden (indiscernable) and false (misconstrued) [82]. Verbeek (2006) states that affordances are similar to scripts, as described by Akrich (1992) and Latour (1992), i.e., they exert influence on users to act in particular ways [226] [5] [124]. 
Shu et al. studied the relationships among a product's affordances, specifically users' perceived affordances and designers' intended affordances. User-perceived affordances are described as either perceptible or false, depending on whether they are present in the object. Of particular interest are false affordances, since they lead to significant user frustration. Also of interest are designer-intended affordances, because products that do not afford intended uses represent a failure in design [186].

\subsubsection{Lead users in affordance-based approach}

Affordance-based methods emphasize what users will think of doing with objects, enabling designers to better understand products from the user's perspective, which may lead to insights on how users can be guided to interact with the product in different, sometimes surprising ways. For example, Son \& Shu (2012) noted that products which collapse and fold to support portability lead to spontaneity in carrying out sustainable behavior, e.g., a compact reusable shopping bag better supports spontaneous shopping than a bulkier bag [190].

In addition to observing average users common to user-centered design, one approach taken at University of Toronto in identifying novel insights begins with seeking lead users in resource conservation. These insights are then abstracted into principles and applied in ways to encourage conservation in mainstream users. Von Hippel (1986) defined lead users as those who have needs in advance of the mainstream, and have often devised their own solutions for their unmet needs [228]. For example, text messaging was reportedly first used by deaf people, who have a clear need for such communication. However, text messaging has proven itself widely relevant to the general, hearing population.

Srivastava \& Shu (2013a) defined as lead users in resource conservation, those who conserve more than the mainstream, e.g., due to cultural values or lack of resources [193]. For example, OldOrder Mennonites were selected as lead users in resource conservation. Their discrete-unit resources, e.g., logs of firewood, buckets of water, and cans of kerosene, were observed to contrast with the continuously flowing electricity and water of mainstream society. An experiment confirmed that mainstream participants performing a washing task using discrete quantities of water (in containers) used less water than when using continuous-flow water from a faucet. Finally, products that incorporate principles such as discretization aim to transfer relevant strategies to mainstream users. For example, discretization can be incorporated in practical ways into mainstream products such as showers, as shown in Figure 4 [193]. Affordances corresponding to resource discretization include imparting to the user: a suggested quantity for consumption, awareness of rate of use, and of the amount of resource remaining [194]. The effectiveness of such products can be validated by studying whether working prototypes can reduce resource consumption over extended periods.

Bhamra et al. used "clever design" to describe innovative product design that decreases environmental impacts without changing user behavior. An example was given of an integrated toilet and washbasin, which decreases water use by re-using water for handwashing to flush the toilet [25]. Such clever designs could potentially be expedited by watching lead users in resource consumption. Such lead users could also emerge through actual or simulated circumstance, e.g., during a power outage or water shortage, where one would be more creative in resource use.

Lead-user insights can often be abstracted and implemented as physical product affordances. Srivastava \& Shu (2013b) investigated how affordances can be used to design products that support sustainable behavior, i.e., enable, encourage, guide, or steer desired behavior [194]. In addition to the Old Order Mennonites, relevant lead users include individuals who transport bulky items while walking, biking and using public transit [191] and individuals who maintain indoor temperatures much closer to ambient outdoor temperatures in both summer and winter [148].

Lead users have been shown to contribute to innovation in design in general, as well as specifically related to sustainability. Other lead users include Bangladeshis [196] and Do-It-Yourselfers (DIYer), such as "IKEA Hackers", who repurpose furniture for aesthetic as well as functional reasons [123]. Such DIYers may be lead users in being able to recognize alternative uses for products and thus effectively substituting the need for new products by extending the functional life time of products broadly perceived as obsolete. Such lead users are more likely to recognize and make product modifications to improve use efficiency, which could be implemented in subsequent versions of the product. Lead users can also be found in FabLabs or makerspaces that foster sustainability-oriented behavior [113], e.g., by hosting repair cafes [141].

\subsubsection{Outlook on affordance-based approach}

Although the concept of affordances has long been mainstream in the field of human-computer interaction, researchers have only begun to explore affordances in lieu of functions as a basis for mechanical design [28]. Physical affordances are inherently more difficult than functions to study, understand, and predict, as they have to do with how users perceive physical objects, whether or not users are aware of, and whether or not designers intended, such perceptions. In addition, there are theoretically an infinite number of ways that different users can interact with a physical product, where there are more limited ways of interacting with software artifacts, e.g., text boxes, radio buttons and pull-down menus. With respect to PEB, Srivastava \& Shu (2015) noted the large number of ways in which potential consumers misinterpreted concepts intended to encourage PEB [197].

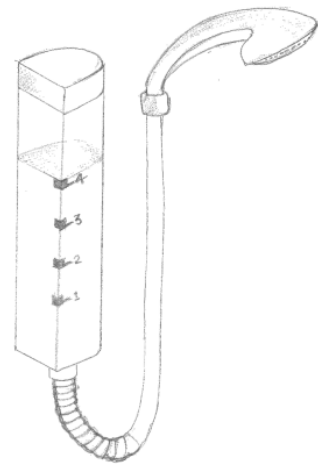

Figure 4: Water-conserving shower concept that incorporates discretization and also suggests maximum quantity [193][194].

\subsection{Towards individualized interventions}

Social scientists have also studied individual differences regarding PEB. Milfont et al. (2006) found that European New Zealanders consider environmental issues according to biospheric concern, i.e., as costs or benefits to ecosystems. In contrast, Asian New Zealanders were found to consider environmental issues more on a personal basis, i.e., egoistic environment concern. Such results suggest that environmental education campaigns could emphasize different aspects of environmental issues when targeting different ethnic groups [147]. More generally, Milfont's (2012) review of cultural differences in environmental engagement points to affluence and value orientations as the main determinants across cultures [146]. Hirsh et al. (2012) also suggest personalized persuasion by tailoring appeals to the intended recipient's personality traits to increase the messages' effect [103]. Hirsh (2014) examined "whether nationally aggregated personality traits can be significant predictors of a country's environmental sustainability," towards interventions targeted towards specific groups of individuals [104]. 
Regarding different goals that underlie relevant behaviors, Kormos et al. (2015) found that messages which highlight descriptive social norms increased sustainable transportation behavior relative to private vehicle use for commuting, i.e., school, work, but not non-commuting, i.e., appointments, shopping, leisure, purposes [118]. Therefore, different factors may affect closely related behaviors, and require different solutions.

\subsubsection{Further motivation to address individual differences}

In addition to the range of product versus user in control shown in Figure 1, product designers have considered other ways of developing product interventions. Tromp et al. (2011) discussed interventions with respect to force (strong vs. weak) and salience (hidden vs. apparent) [217]. Lockton (2012) described designers' models of users, and that designers choose intervention approaches based on how they believe the user acts [134].

Design researchers also identified the need for different PEB interventions based on individual differences. Withanage et al. (2014) studied energy-use behavior related to cooking, and found two types of users to target: 1) those who did not know the correct behavior to perform, and thus could benefit from more knowledge and 2) those who did know the correct behavior, but would not perform it, and thus needed intervention other than information [233]. Since the first user type may become the second user type after gaining knowledge, they may also benefit from interventions intended for the second user type. Regarding eco-design, Telenko \& Seepersad (2014) noted that levels of income, knowledge and available time also affect how users interact with products [207].

There are also many reasons why eco-products are not adopted. Yim \& Herrmann (2003) explored why consumers do not buy ecoproducts, using consumer behavior analysis to identify technical aspects of eco-products to increase their appeal [239]. GoucherLambert \& Cagan (2014) report that the addition of environmental information to a product alters how it is perceived by users, with different consumers assessing that additional information differently [89]. Goucher-Lambert et al. (2017) used neuroimaging to understand moral product preference judgments involving sustainability. They observed that functional attributes become more important and esthetic attributes become less important when sustainability is a factor [90]. Gromet et al. (2013) showed that promoting the energy-efficiency benefits of a product can negatively affect its adoption due to political polarization around environmental issues [93]. Their first study showed that politically conservative individuals placed less value on reducing carbon emissions and supported investment in energy-efficient technology less than those who were politically liberal. In a second study, participants had a choice between buying Compact Fluorescent Light (CFL) or incandescent bulbs. While the CFL bulbs were more expensive than incandescent bulbs, participants generally agreed that the CFL bulbs were better with respect to function, savings over the product's lifetime, and environmental benefit. However, politically moderate and conservative participants were deterred from choosing the CFL over an incandescent bulb, when the CFL bulb was labeled with an environmental message. These participants were more likely to choose the CFL bulb when it was unlabeled, because the environmental label directly conflicted with their dislike of investments in energy-saving measures [93]. Thus, promoting a feature meant to increase appeal of a product may actually deter some consumers. These results add another dimension to the limitations of information-based campaigns.

\subsubsection{Approaches for designers to address user differences}

Researchers can address user-group differences in different ways, including case-by-case customisation. Kok et al. (2011) applied Intervention Mapping, originally developed for health promotion initiatives, to reduce home energy consumption [114].
Recognizing that different groups have different objectives, they recommended tailoring interventions by executing a six-step Intervention Mapping process for each group. Klein et al. (2011) developed a mobile-phone application (app) that prompts users to engage in healthy behavior [110]. Using a model that combines many behavior-change models, the app asks the user questions to determine values for each of its parameters, and then provides a series of prompts and tasks customized to the user's profile. The modeling of heterogeneous consumer preferences itself is a complex problem. Zhao \& Thurston (2013) used a mathematical model to forecast consumer demand based on varying preferences to maximize profits from end-of-life and initial sales [243]. Another way of addressing different needs for PEB follows.

\subsubsection{Multi-motive behavior-change framework}

To address differences between users, Srivastava \& Shu (2015) adopted an approach originally applied to agricultural behavior change [197]. Pannell et al. (2006) and Farmar-Bowers \& Lane (2006) found that Australian farmers had different goals and motivations, responding best to interventions toward resourceconservation practices that were consistent with their interests [167] [72]. Greiner et al. (2007) categorized these farmers under three sources of motivation (financial, social, and environmental). They then determined the types of incentives that matched these motivations, finally recommending a combination of incentives to motivate as many farmers as possible to increase their resourceconserving behavior [90]. Srivastava \& Shu generalized Greiner et al.'s motivation types as: egoistic, sociocultural and altruistic. While users could be otherwise motivated, or be insensitive to any motivation, this is a starting point to better understand how to develop concepts for different sources of motivation.

Egoistic motives have to do with the user's self-interest. Similar to traditional design objectives, such motives include a desire for improved convenience and performance, e.g., reduced time, cost, effort and steps of operation. These motives are similar to the selfenhancement values in the Schwartz Theory of Basic Values discussed earlier [182]. Specific to PEB, Davoudi et al. identify concern for oneself as a major antecedent of energy consumption behavior [49]. Three of the six drivers of product utility identified in a study of consumer purchasing behavior, productivity, simplicity, and convenience, can be categorized as egoistic [30].

Sociocultural motives describe the desire to be perceived positively by one's family, peers and other social group. Social attitudes and norms, discussed earlier in detail, have been shown to influence environmentally relevant behavior, such as whether people waste food [67], dispose of old possessions [171], adopt energy-saving home innovations [36], and reduce water consumption [41]. These motives are also manifested as the socialrisk and potential image enhancement users assess in new products [30]. Greiner et al. noted that farmers who were most interested in maintaining a tradition of farming and community respect, responded best to image-enhancing interventions [90]. Peschiera et al. (2010) and Toner et al. (2014) found people were most successful in conserving energy or motivated to change behavior when they believed that their current behavior differed from an important peer or reference group [170] [213].

Altruistic motives are related to values of self-transcendence in the Schwartz Theory of Basic Values [182], describe the user's concern for others and the environment, and are well documented as an influence on behavior. Greiner \& Gregg (2011) found that many Australian farmers were motivated primarily by a desire to conserve the land and be good stewards [92].

\subsubsection{Testing of multi-motive behavior-change framework}

The framework was tested empirically by developing concepts, each intended to address single motive types. Online respondents were asked to evaluate these concepts, where participant 
preferences were compared with self-assessed motivation types. Deviations from expected results were mainly due to unexpected perceptions, both positive and negative, of the concepts. However, there may be practical value in explicitly considering different motivation types rather than the ability to target a single type in a given concept [192].

\subsubsection{Multi-motive behavior-change concept matrix}

Figure 5 shows a matrix-based design tool that incorporates this user-motivation framework, where the three major rows correspond to the three types of motives in this framework. The columns of the matrix correspond to the range of user versus product control that concepts allow shown in Figure 1. This range integrates the work of several researchers, from levels of automation [185] to work specific to sustainable behavior [242]. Left-most-column concepts offer information intended to persuade users to perform behavior change. Right-most-column concepts give the user no choice but to perform the proposed behavior. The range was explicitly divided to encourage exploring levels beyond information and feedback, which dominate concepts proposed for behavior change. In this tool, completing the leftmost column provides value by clarifying the underlying message for subsequent columns.

Each row is further split into positive interventions that reward the desired behavior versus negative interventions that penalize the undesired behavior. Behavior change can also be addressed by curtailing one behavior or promoting an alternative, where the positive intervention could reward the desired alternative. This division gives yet another perspective for designers to consider. Other researchers, e.g., Daae \& Boks (2014) also divide strategies along the dimension of encouragement, i.e., whether to promote or discourage a behavior, in design for behavior-change [47].

\begin{tabular}{|c|c|c|c|c|c|c|c|}
\hline & $\begin{array}{l}\text { INFORMATION } \\
\text { General Messages }\end{array}$ & $\begin{array}{c}\text { FEEDBACK } \\
\text { Data reflecting } \\
\text { user performance }\end{array}$ & $\begin{array}{l}\text { ENABLING } \\
\text { Make } \\
\text { behavior } \\
\text { easier to do }\end{array}$ & $\begin{array}{l}\text { ENCOURAGING } \\
\text { Advise user on } \\
\text { which behavior to } \\
\text { perform }\end{array}$ & $\begin{array}{l}\text { GUIDING } \\
\text { Recommend action } \\
\text { to user via } \\
\text { messages/cues }\end{array}$ & $\begin{array}{l}\text { STEERING } \\
\text { Selects best } \\
\text { action, cues user } \\
\text { to perform action }\end{array}$ & $\begin{array}{l}\text { FORCING/ } \\
\text { AUTOMATION } \\
\text { User /product } \\
\text { must do action }\end{array}$ \\
\hline \multirow{2}{*}{$\begin{array}{r}\text { EGOISTIC MOTIVES } \\
\text { Minimize } \\
\text { cost/time/steps; } \\
\text { Increase fun/ } \\
\text { efficiency; }\end{array}$} & \multirow{2}{*}{$\begin{array}{l}\text { Signage: "Turning off } \\
\text { lights saves money." } \\
\text { / "Keeping lights on } \\
\text { wastes money." }\end{array}$} & \multirow{2}{*}{$\begin{array}{l}\text { Show amount of } \\
\text { money [saved/ } \\
\text { wasted] by [turning } \\
\text { off/not turning off] } \\
\text { lights. }\end{array}$} & \multicolumn{2}{|c|}{$\begin{array}{l}\text { (Financial) rewards for turning off } \\
\text { lights. }\end{array}$} & \multirow[t]{2}{*}{$\begin{array}{l}\text { Install light switch } \\
\text { at same level as, } \\
\text { next to door knob. }\end{array}$} & \multirow[t]{2}{*}{$\begin{array}{l}\text { Have light switch } \\
\text { partly block door } \\
\text { knob when on. }\end{array}$} & \multirow{6}{*}{$\begin{array}{c}\text { Exit door only } \\
\text { opens after } \\
\text { light is turned } \\
\text { off } \\
/ \\
\text { Lights turn off } \\
\text { automatically }\end{array}$} \\
\hline & & & $\begin{array}{l}\text { (Financial) per } \\
\text { turning off ligh }\end{array}$ & ties for not & & & \\
\hline \multirow{2}{*}{$\begin{array}{r}\text { SOCIO-CULTURAL } \\
\text { MOTIVES } \\
\text { Increase prestige } \\
\text { /sense of belonging; } \\
\text { Join trends; }\end{array}$} & \multirow{2}{*}{$\begin{array}{l}\text { Signage that shows: } \\
\text { Others [approving } \\
\text { /disapproving] those } \\
\text { who [turn off lights / } \\
\text { keep lights on] when } \\
\text { leaving. }\end{array}$} & \multirow{2}{*}{$\begin{array}{l}\text { Show number of } \\
\text { [likes/ dislikes] on } \\
\text { social media for } \\
\text { light [turning } \\
\text { off/not turning off] } \\
\text { behavior. }\end{array}$} & $\begin{array}{l}\text { Make light-swi } \\
\text { highly visible } t\end{array}$ & $\begin{array}{l}\text { ing-off behavior } \\
\text { ther people }\end{array}$ & \multirow{2}{*}{\multicolumn{2}{|c|}{$\begin{array}{l}\text { Require name badge to turn on and off } \\
\text { lights. Show number of light turn-ons } \\
\text { vs. turn-offs for each name near light } \\
\text { switch. }\end{array}$}} & \\
\hline & & & $\begin{array}{l}\text { Make not-swit } \\
\text { behavior highl } \\
\text { people. }\end{array}$ & $\begin{array}{l}\text { ng-off-light } \\
\text { isible to other }\end{array}$ & & & \\
\hline \multirow{2}{*}{$\begin{array}{r}\text { ALTRUISTIC } \\
\text { MOTIVES Minimize } \\
\text { environmental } \\
\text { impact; Improve } \\
\text { lives of others; }\end{array}$} & \multicolumn{2}{|c|}{$\begin{array}{l}\text { Reward: Tell user ecological benefits of } \\
\text { resources (they) saved. }\end{array}$} & $\begin{array}{l}\text { Resources save } \\
\text { environmental }\end{array}$ & $\begin{array}{l}\text { goes to } \\
\text { iuses. }\end{array}$ & \multirow{2}{*}{\multicolumn{2}{|c|}{$\begin{array}{l}\text { Light switch consists of two pictures } \\
\text { that are slid into and out of view. } \\
\text { Picture of [forest/desert] corresponds } \\
\text { to light [off/on]. }\end{array}$}} & \\
\hline & \multicolumn{2}{|c|}{$\begin{array}{l}\text { Penalty: Tell user ecological costs of } \\
\text { resources (they) wasted. }\end{array}$} & \multicolumn{2}{|c|}{$\begin{array}{l}\text { Resources wasted goes to anti- } \\
\text { environmental causes. }\end{array}$} & & & \\
\hline
\end{tabular}

Figure 5: Multi-motive behavior-change concept matrix for turning off lights when leaving room. Italicized concepts are abstract.

\section{Approach using automated impact minimization based on self-learning usage anticipation}

Computer science concepts as the Internet-of-Things (IoT) and Artificial Intelligence (AI) enable an approach to automatically reduce the resource consumption of devices. As such, the strategy is no longer to reduce environmental impact through users' PEB, but to minimize impact directly while assuring product functionality. The approach thus corresponds to productcontrolled strategies, referred to as intelligent products by Lilley et al. (2005) in the methodological framework of Section 1.5.
The multi-motive behavior-change concept matrix in Figure 5 is completed with concepts towards the desired behavior/outcome of turning off lights (or other resource-consuming device) when leaving a room. Italicized concepts (in the enabling/ encouraging) columns are left abstract, while the remaining concepts are more concrete, to demonstrate yet another possible dimension. In addition, some columns are combined in some concepts, and some concepts combine both reward and penalty rows.

\subsubsection{Multi-motive behavior-change design matrix conclusion} Srivastava studied expert use of this design matrix, and suggested collapsing the more similar columns together, i.e., information with feedback, and enabling with encouraging, etc. [192]. Although other researchers may use more levels, e.g., Daae $\&$ Boks differentiate nine levels in their scale of user control [47], such a large number may not be necessary for concept generation. In the end, both the numbers of columns and rows can be changed, e.g., Steg et al. differentiate between altruistic values as concern for others and biospheric values as concern for the environment [52] and recommend including hedonic values in PEB studies [201]. In addition, other categories of motivation [26], or difference could be used in lieu of the row and/or column categories shown.

The ultimate benefit of such a tool may be in improving designer understanding of the problem by considering several different perspectives, e.g., different user motivations, levels of user control and positive versus negative reinforcement. In completing the matrix, designer understanding of the parameters and constraints of the problem may be improved through sheer repetition. Designers can also use such a matrix to determine 1) the breadth of appeal for a concept, and 2) the number of ways in which a concept will influence users. The most effective concepts will likely combine several parts of the matrix, i.e., appeal to more than one type of user and use more than one strategy to persuade them. 


\begin{tabular}{|c|c|c|}
\hline $\begin{array}{l}\text { Location of } \\
\text { intelligence }\end{array}$ & $\begin{array}{c}\text { Level of } \\
\text { intelligence }\end{array}$ & $\begin{array}{l}\text { ation level } \\
\text { elligence }\end{array}$ \\
\hline $\begin{array}{l}\text { Intelligence } \\
\text { through network }\end{array}$ & formation handling & $\begin{array}{l}\text { Intelligent } \\
\text { item }\end{array}$ \\
\hline $\begin{array}{l}\text { Intelligence } \\
\text { at object }\end{array}$ & ecision mal & $\begin{array}{l}\text { Intelligent } \\
\text { container }\end{array}$ \\
\hline
\end{tabular}

Figure 6: Intelligent products classification [149]

\subsection{Intelligent systems}

The subject fits in the emerging domain of Intelligent Products. Various authors have tried to universally define intelligent products. The most relevant definition for the applications considered in this section is the one proposed by Ventä (2007), which states that intelligent products and systems 1) continuously monitor their status and environment, 2) react and adapt to environmental and operational conditions, 3) maintain optimal performance in variable circumstances, also in exceptional cases and 4) actively communicate with the user, environment or with other products and systems [225]. As opposed to other definitions, this description is more focused on decision-oriented products and on the running and maintenance of products in use. However, all definitions focus on certain aspects and thus do not cover the entire field of intelligent products. Therefore, Meyer et al. (2009), in a special issue on intelligent products in the Computers in Industry journal, introduced a classification of intelligent products that covers all aspects of the field [142]. This classification, illustrated in Figure 6, consists of three dimensions: level of intelligence, location of intelligence and aggregation level of intelligence. For this discussion, only the level of intelligence dimension is of interest. The applications covered later on in this section correspond to intelligent products with decision-making capabilities. Editors of the special issue, Framling et al. (2009) state, "Although many academic and technical challenges remain, perhaps the greatest challenge in this space is in demonstrating that intelligent products are not simply gimmicks but that they have a valuable and useful role to play in a more energy- and material-efficient, cleaner society" [76].

Hazas et al. (2011) identify the following four broad approaches in the history of domestic energy consumption research [99]:

- provide feedback on energy consumption details to users;

- implement economics-based strategies, such as incentives, to reduce energy demand;

- examine social factors concerning energy-use practices;

- intervene using technology to sense and control energy usage.

This categorization of energy consumption reduction strategies also holds for the more general case of resource consumption. The first three categories correspond to the approaches covered in the previous section, i.e. they aim to change user behavior. The last approach, next to enabling feedback systems and strategies requiring active user involvement, also allows for an automatic reduction in consumption. For this purpose, infrastructure, buildings and appliances should be made smarter, more adaptive and should work in harmony with occupants as well as energy providers to find new ways to reduce consumption and carbon emissions [99]. This is facilitated by intelligent control systems. However, a trade-off exists between system functionality and resource conservation. That is, user needs must be satisfied while reducing consumption. Therefore, these intelligent controllers aim to accurately predict future usage and adjust control accordingly. Hereto, machine learning techniques are used to construct a prediction model from historical data, including historical usage, temporal and optionally other environmental information. Such knowledge is then exploited to train a classification model which can forecast system usage based on new data.
A methodology to determine the reduction potential by intelligent control of any given application was developed by Duflou et al. (2016), as part of the PERPETUAL project [169]. The authors identified the following selection of system and usage features that influence the reduction potential [60]:

- Consumption rates $\mathrm{P}_{\text {state }}$ of different system states (e.g. operational, standby);

- Tardiness T, or inertia, of a system, i.e. the duration of a transition from one state to another;

- User Tolerance UT, the level of discomfort that is acceptable;

- Variability $\mathrm{V}$ of the usage in terms of statistical repeatability of usage patterns;

- Time Window TW defined as the period of time during which usage can occur;

- Time Fraction TF representing the maximum potential fraction of usage time within TW that can be saved;

- and finally, the Fractionality F representing the number of discrete usage blocks within TW.

Once these variables are determined, it is possible to compute the Consumption Reduction Potential CRP and related Impact Reduction Potential IRP:

$$
\begin{gathered}
C R P=T F * T W * \Delta P_{\text {operational }}+(1-F) *\left[\left(\Delta P_{\text {startup }} * t_{\text {startup }}\right)\right. \\
\quad+\left(\Delta P_{\text {shutdown }} * t_{\text {shutdown }}\right)
\end{gathered}
$$

where $\Delta P_{\text {state }}$ represents the difference between $P_{\text {state }}$ and $P_{\text {standby }}, t_{\text {state }}$ the duration of a transition from standby to a certain state (e.g. startup) or vice versa (e.g. shutdown) and $E I$ the environmental impact per unit resource consumption.

These features and their influence should be taken into account when designing an intelligent control system in order to optimize the consumption-functionality trade-off. Preferably, the usage variability is sufficiently low as to assure good predictability. Otherwise, adequately high user tolerance levels are required. Furthermore, low fractionality is desirable especially for systems with a high inertia. As an illustration, the potential amount of time usage can be saved by anticipative control is depicted in function of the time fraction, system tardiness and fractionality in Figure 7.

\subsection{Methods and techniques}

The number of research contributions on smart, resource efficient systems, such as smart home applications and electric vehicles, is substantial. In general, the approaches can be classified into the categories pervasive computing, usage profiling /prediction and intelligent control. This section presents a brief description of the different methods and their application for environmental sustainability.

\subsubsection{Pervasive computing}

Pervasive computing, or ubiquitous computing, is a concept involving the embedment of microprocessors into everyday objects which enables computing and communication, as its name implies, anywhere and everywhere. Therefore, it is well suited to address many of the core challenges in environmental sustainability, such as monitoring the state of the physical world; managing the direct and indirect impacts of large-scale human enterprises such as agriculture, transport, and manufacturing; and informing individuals' personal choices in consumption and behavior [235].

Sustainability has also received increasing attention in the related field of Human Computer Interaction (HCI). DiSalvo et al. (2010) indicate the following five genres of sustainable HCI [55]: 1) Persuasive technology, where systems are designed that try to convince users to adopt more sustainable behavior; 2) Ambient awareness on the other hand merely informs and makes the users aware of their wasteful behavior through ambient displays; 3 ) 
Sustainable interaction design is about rethinking the role and outcome of design; 4) Formative user studies aim to understand users' attitudes towards sustainability as a first step to new design; and 5) Pervasive and participatory sensing deals with sensors to monitor and report on environmental conditions and using the gathered data to change those conditions.

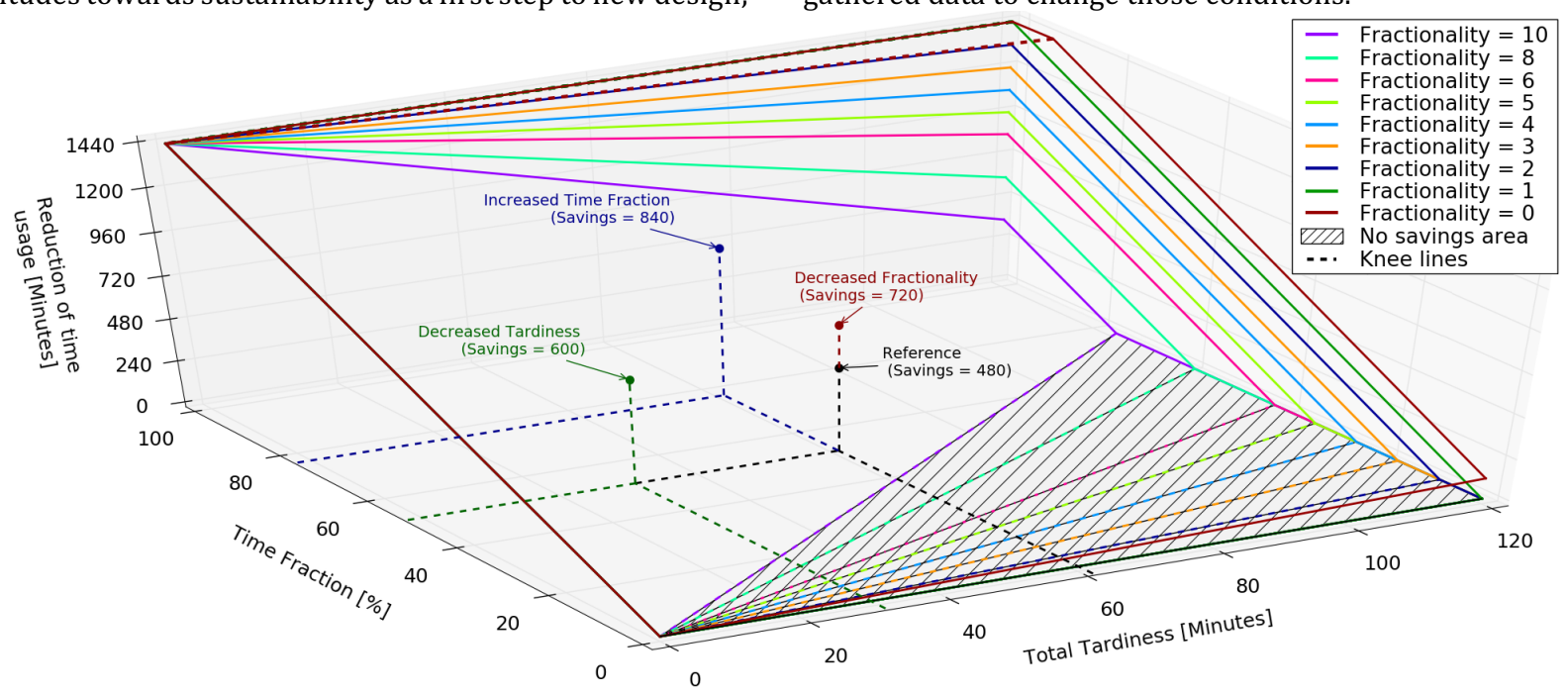

Figure 7: Potential reduction of usage time as a function of Total Tardiness and Time Fraction for different Fractionality values (Duflou et al. 2016) [60].

Three labeled data points show that larger Time Fraction and lower Tardiness and Fractionality all enable higher savings.

Although these techniques primarily seem suited for systems that try to steer user behavior, they enable the creation of automatic systems by exploiting the collected data in an intelligent way. Cardenas-Tamayo et al. (2009) and Amft et al. (2011) present a selection of pervasive computing applications for environmental sustainability [32] and smart energy systems [6].

\subsubsection{Usage profiling/prediction}

This category of methods extends pervasive computing by intelligently using the data collected by sensors or other connected devices to reduce consumption. This approach is situated within the ambient intelligence field. Ambient Intelligence (AmI) is similar to Pervasive Computing but focuses more on the user, the idea of human-centered design and the intelligence required to enable the system to anticipate the needs of its user(s) [11]. Augusto (2007) defined AmI as: "A digital environment that proactively, but sensibly, supports people in their daily lives", which emphasizes that intelligence is a fundamental element of an AmI system [9]. Furthermore, Augusto describes it as the confluence of ubiquitous/pervasive computing and artificial intelligence. Such systems facilitate a reduction in resource consumption by anticipating user requirements and hence future usage. Instead of a user learning to use new products or technologies, an AmI system tailors its behavior to the user by learning preferences, needs and habits in a non-intrusive, transparent way. Enhanced efficiency of devices can be achieved by such a self-learning AmI system. Figure 8 illustrates the general process of such systems.

Machine learning and AI techniques are employed to learn from user behavior and to enable the prediction of future usage. For example, data from sensors collecting occupancy information can be used to predict the future occupancy of a certain room and to steer the heating schedule accordingly, instead of using a fixed, inflexible heating schedule. Furthermore, as users' requirements must be satisfied, their preferences, e.g., comfort, temperature, should be learned from the data and user feedback.

Some techniques extract patterns, or so called profiles, from the data. In the heating example this would correspond to different occupancy patterns, e.g., on workdays and weekends. These profiles are then exploited to forecast future usage.
The predictions enable saving energy when it is expected that the appliance will not be used for a certain period of time and form the input for some control mechanism.

\subsubsection{Intelligent control}

In the AmI system described in Figure 8, intelligent control corresponds to the implementation of the acting stage. The control method incorporates the learned knowledge (e.g. profiles, system model, predictions) to optimally control the system regarding functionality and resource consumption. In general, intelligent control refers to a class of control techniques that employ $\mathrm{AI}$ methods such as neural networks.

A widely used control strategy is Model Predictive Control (MPC) which relies on a dynamic model of the process to optimize its control. In the previously used heating example, the characteristics of the environment, such as inertia, define the system model. Knowledge of the required amount of time for a room to heat up enables a more efficient control strategy. Furthermore, room occupancy and weather forecasts can be incorporated into the MPC controller. Accurate predictions of future heating requirements allow optimal control of the heating system. As such, the control mechanism optimizes the aforementioned trade-off between system functionality and resource consumption. Proper weighting of the comfort and resource preservation targets allows to determine an objective function for the optimization procedure.

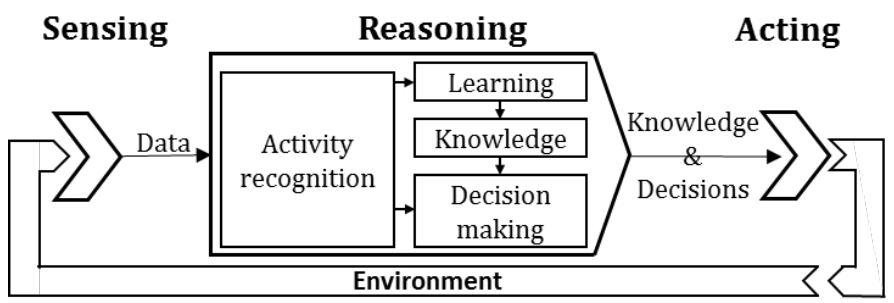

Figure 8: Process of an Ambient Intelligence (AmI) system [11]

\subsection{Case studies}

As increasingly more tasks become automated, in combination with the rise of the IoT and environmental awareness, a substantial amount of research has been conducted on selflearning systems to minimize impact while guaranteeing functionality. A wide variety of applications have been studied, 
although smart buildings are by far the most extensively explored subset. This section presents an overview of different applications and is subdivided according to identified important application areas.

\subsubsection{Intelligent buildings}

The US Intelligent Building Institute (IBI) defines an intelligent building as "one which provides a productive and cost-effective environment through optimization of its four basic elements, including structures, systems, services and management and the interrelationships between them" [234]. Its European counterpart, the Intelligent Building Group (IBG), specifies it as "one that creates an environment which maximizes the effectiveness of the building's occupants, while at the same time enabling efficient management of resources with minimum life-time costs of hardware and facilities" [234]. Both definitions contain the aspect of human comfort as well as resource-efficiency. Satisfying comfort requirements while reducing energy consumption in intelligent buildings is the goal of Building Energy and Comfort Management Systems (BECMS) [163]. Occupant presence and activity information are highly correlated with energy demand of heating, cooling, lighting and appliances; therefore, BECMS can substantially reduce energy consumption by regulating building control according to actual user needs [163].

\section{Heating, Ventilation and Air Conditioning (HVAC)}

Heating, Ventilation and Air Conditioning (HVAC) is typically the main energy consumer in buildings. In the US, in both commercial and residential buildings, HVAC accounts for more than $40 \%$ of total building energy consumption [62][63]. Currently, HVAC control is mainly scheduled manually, i.e., the heating schedule is manually programmed by the user based on experience. However, these schedules are usually defined once during installation and are rarely updated afterwards. This can lead to outdated, inaccurate schedules and thus increased energy consumption and diminished comfort level. Peffer et al. (2011) reported that only half the programmable thermostats in the US are used as intended, due to complex user interfaces, lengthy manuals and social and practical barriers [168]. In addition, at least $30 \%$ of US households do not use their thermostats' programming feature [143].

Significant savings can be obtained by regulating HVAC according to actual user needs, e.g., Erickson et al. (2013) estimates approximately $30 \%$ energy savings based on live tests [65]. Occupancy information, typically gathered using a sensor network, allows intelligent control systems to reduce energy consumption and improve user comfort. These systems are able to predict user presence. Hence, they can anticipate future usage and, for example, start heating up the house such that the target temperature is reached upon user arrival. Furthermore, vacant rooms will no longer be unnecessarily conditioned. Finally, occupancy information, possibly derived from $\mathrm{CO}_{2}$ sensors, also facilitates demand control ventilation. Nowadays, many spaces are needlessly over-conditioned as the control system assumes maximum occupancy. Demand control ventilation therefore adjusts the ventilation rate based on the number of occupants, which further reduces HVAC energy consumption. Posselt et al. (2015) present a computational fluid dynamic model coupled with a wireless sensor network to estimate temperature and air flows within factory buildings. The approach aims to improve control strategies of HVAC systems towards a more energy-efficient and demand-oriented climate conditioning [172].

Recently, smart home applications, and smart thermostats in particular, received increasing attention in both research and industry. The former is briefly discussed next, while the latter is illustrated by the recent emergence of thermostat solutions like Google's Nest, Anna by Eni, Qivivo, Heat Genius, etc. In research, AI techniques are used to model and predict user behavior. More specifically, user presence is detected and predicted to facilitate tailored HVAC control. Mamidi et al. (2012) implemented a sensor network to model and predict the number of occupants using machine learning techniques [138]. The predictions are then used to optimize HVAC control for each room. Erickson et al. (2013) report approximately $30 \%$ reduced HVAC consumption using occupancy-based conditioning. In this work, occupancy data were collected by a combined network of cameras and motion sensors and user presence was predicted using a blended Markov chain [65]. Lu et al. (2010) reported similar savings for The Smart Thermostat, which achieved average energy savings of $28 \%$ using basic sensing technology and a hidden Markov model to exploit occupancy and sleep patterns [136]. Mozer et al.'s (1997) Neurothermostat predicts occupancy by combining a neural network with a look-up table of occupancy states indexed by time of day to take advantage of the periodic nature of human behavior [152]. Other well-known techniques for occupancy-driven heating control are the GPS thermostat, which uses GPS information [94] and PreHeat, which uses $k$-nearest neighbors [183], to predict occupancy. Krumm \& Brush (2011) represent the problem of learning presence schedules as a linear matrix problem. They solve it using least squares and combine it with the driving time heuristic of Gupta's GPS thermostat [120]. Kleiminger et al. (2014) analyzed comparative performance on some of these state-of-the-art methods, reporting achievable savings of $6-17 \%$ [109].

Some studies apply user modeling to fully exploit occupancy data [18][50][211][223][224]. User models or user profiles consist of preferences and occupancy patterns, which are identified by clustering techniques that group together similar days. Knowledge of occupants' habits enables the development of HVAC strategies that optimize the trade-off between energy consumption and user comfort. As part of the PERPETUAL project [169], De Bock et al. (2016a) present a smart thermostat that establishes and exploits a user model to predict future occupancy and steer the heating accordingly. The resulting potential energy reduction of 259.2 $\mathrm{kWh}$ per year corresponds to $25.5 \%$ of the total energy consumption for a single-user office in Belgium [50]. Moreover, as user conduct changes over time, the profiling method was adapted in order to handle drifting behavior [51]. All or the majority of the discussed smart heating systems are oriented towards single-user environments or treat a group of users as a single entity. Therefore, Auquilla et al. (2016) extended this case study to a situation with multi-user interactions and conflicting user preferences [10].

Finally, various researchers optimize HVAC systems by anticipating future cooling demand [22][127][128][177][238]. Cooling load prediction techniques are especially useful for HVAC systems with thermal energy storage. As with heating, cooling has a large inertia and requires a predictive model for optimization, which typically uses Artificial Neural Networks (ANN).

\section{Lighting}

Interior lighting is another major source of energy consumption in buildings, accounting for approximately $17 \%$ of the electricity consumed by commercial buildings in the US [63]. In such buildings, lights are typically constantly on during business hours. Significant energy savings can be achieved by automatically switching off lights in unoccupied rooms and by exploiting natural light. The former is based on occupancy sensing, while the latter is known as daylight harvesting. Typically, occupancy-based lighting control systems automatically turn off lights when no movement is detected for a fixed, predefined period of time, i.e. the delay factor. Daylight harvesting on the other hand, conserves energy by sensing the ambient light present in a space and dimming artificial lights accordingly. These two technologies facilitate a substantial reduction in lighting energy consumption. To further reduce consumption, more attention has been paid to individual lighting 
preferences, which also increases visual comfort, leading to increased productivity of occupants [163]. As the cost of salaries typically greatly exceeds energy costs in commercial buildings, [189], many new buildings have Personal Environment Modules (PEMs), through which occupants can control their environment individually and augment their personal performance.

However, the delay factor of occupancy sensors greatly affects both user comfort and energy savings. A large delay factor results in energy waste as vacant rooms are illuminated. A small delay factor facilitates energy savings, but leads to discomfort as lights are turned off when the occupant is present but moving infrequently, e.g., when reading. Also, researchers have observed that people tend not to use their PEMs when their preferences conflict with other users sharing their environment [189]. Artificial Intelligence provides a means to overcome these problems by implementing self-learning usage anticipation strategies. Garg \& Bansal (2000) introduced smart occupancy sensors that use a statistical model to generate an adaptive delay factor based on occupancy behavior, saving an additional 5\% energy [81]. Sandhu et al. (2004) proposed supervised and reinforcement learning techniques to emulate user actions based on sensor data, such as presence and illuminance [179].

Singhvi et al. (2005) present an intelligent lighting control system that optimizes the comfort/savings trade-off using a sensor network [189]. This intelligent lighting control system tunes lighting levels to occupants' preferences, implements daylight harvesting and active sensing, and anticipates user movement. To satisfy the lighting preferences of multiple users, the room is divided into small zones with separate light controls. As a single lamp affects multiple zones, optimal settings that maximize comfort of the users affected by the lamp and minimize energy costs are found by solving a multi-criterion optimization problem using scalarization. The system is thus able to predict lighting levels in each zone and learns how each lamp affects each zone. Energy consumption is further reduced by daylight harvesting and active sensing, the latter of which reduces the consumption of the sensor network. Finally, the system proactively controls lighting by anticipating the movement of users from one room to another. Although predictive lighting drastically increases comfort, it also increases energy consumption since unoccupied adjacent rooms are sometimes illuminated [189].

\section{Hot water control}

This topic was the focus of limited research efforts. Each year thousands of liters of water are wasted by people waiting for hot water to come out of the faucet while cold water flows down the drain. This delay is caused by pipe lag, which results from water remaining in the pipes after previous usage has cooled to room temperature. Hot Water Recirculation (HWR) systems address this problem by continuously circulating hot water through the pipes, and require the installation of a pump and a return pipe from the faucet to the water heater. HWR systems effectively reduce water wastage, but the energy consumption of the pump and the heater to compensate for pipe heat loss can increase yearly electricity costs by more than 360\% [77]. Frye et al. (2013)'s Circulo tackles this problem by circulating hot water just-in-time. Their system collects historical data regarding hot water usage and identifies patterns using a Naive Bayes Classifier to predict future hot water events. The input data of the classifier consist of the time of day, day of the week and the amount of time hot water consumed in the previous 15, 60 and 120 minutes. When usage is predicted, the pump is enabled to circulate water in the pipes to the heater, and hot water from the heater to the faucet. In this way, Circulo reports a reduction in energy consumption of HWR systems by $30 \%$ while providing instantaneous hot water over $90 \%$ of the time [77].

Prodhan \& Whitehouse (2012)'s Hot Water DJ aimed to reduce the energy wasted by heat loss of water pipes, which amounts to
$20 \%$ of the total energy consumption of a water heater. Furthermore, the hot water tap is often turned off before the hot water effectively reaches the faucet. Including these so-called short events, total pipe loss accounts for $24 \%$ of total energy consumption [174]. As most faucets are typically used for the same activities (e.g., the kitchen sink is used for washing dishes), gathering usage information such as temperature and pipe lag allows one to infer temperature and delay patterns for each faucet. The Hot Water DJ intelligently selects an optimal water temperature for each faucet based on its usage history, and intelligently introduces a delay to anticipate short events. Next, water of the required temperature is provided to each faucet by adding cold water to the hot water using a mixer located close to the hot water tank. As a result, the water that remains in the pipes after the usage event is less hot and thus less energy is wasted. The user has a "comfort" button to control the temperature and delay settings. If hotter water than provided is required, the user can override the system by turning the hot water tap off and on multiple times, increasing the water temperature by $5^{\circ} \mathrm{F}$ each time. Prodhan \& Whitehouse report that energy savings of $10-18 \%$ can be achieved by the Hot Water DJ [174].

\section{$\underline{\text { Appliances }}$}

Energy conservation opportunities for appliances consist of dynamic power management and load shifting techniques. Dynamic power management refers to the process of adapting the power mode of a system according to its workload. When idle, an appliance is typically switched to standby mode, which usually draws a small amount of power. However, as most appliances remain in standby mode for a long period of time, this ultimately may account for a significant amount of energy consumption. Forecasting device usage allows more intelligent and energy efficient power management by completely powering off the device when usage is unexpected, and switching to standby or active mode in anticipation of future demand [53][126][188]. Standby power consumption is thus reported as reduced by $27-$ $44 \%$ [126]. Within the PERPETUAL project, De Hauwere et al. used reinforcement learning to optimize control of a coffee machine in an office environment, to balance user comfort and energy consumption, enabling potential yearly savings of $67-88 \%$ [53].

Load shifting on the other hand involves intelligently scheduling appliance usage to minimize peak demand. Shifting loads to offpeak periods avoids the operation of peaking power plants and the corresponding carbon emissions. Furthermore, as energy tariffs are cheaper during off-peak periods, load shifting also reduces cost for the user. However, user comfort should also be taken into account since rescheduling to night time, for example, may not always be acceptable. Forecasting appliance usage enables suggestions that minimize the impact on the user while reducing cost and carbon emissions by determining the best time for appliance use [19][20][70][218]. Appliance usage forecasting systems typically consist of usage profiling [34] and prediction techniques [35]. In manufacturing, Beier et al. (2017) developed a method that allows real-time control of manufacturing systems, aiming at a high utilization of (on-site) generated renewable energy without compromising system throughput [21].

\subsubsection{Electric vehicles}

Electric vehicles (EV), including hybrid electric vehicles (HEV) and plugin hybrid electric vehicles (PHEV), can reduce fossil-fuel consumption and air pollution caused by conventional combustion engine based transportation. However, widespread adoption of EVs will introduce technical issues such as overloading and increasing power losses in future smart grids. Gharavi \& Ghafurian (2011) define the Smart Grid as "an electric system that uses information, two-way, cyber-secure communication technologies, and computational intelligence in an integrated fashion across 
electricity generation, transmission, substations, distribution and consumption to achieve a system that is clean, safe, secure, reliable, resilient, efficient, and sustainable" [84].

A wide range of solutions has been proposed to overcome the problems potentially linked to intensive use of electric vehicles. García-Villalobos et al. (2014) present a review of smart charging approaches [79]. Currently, due to limited penetration of PEVs, a no-integration strategy (uncontrolled charging) or a passive strategy (typically off-peak charging, which encourages charging during night time) is implemented. The main drawback of these strategies is that they produce sudden increases in power demand as the charging process for most PEVs would start almost simultaneously. Smart charging on the other hand facilitates technical and economic benefits by scheduling PEVs charging profiles based on anticipated demand and user convenience. Two smart charging approaches are distinguished, namely valley-filling and peak-shaving, which can be implemented by either centralized or decentralized control. In the centralized case, the aggregator is responsible for managing the charging process of PEVs. Historical data and user preferences are used to forecast demand, which in turn is used to define the PEVs' charging schedules. With decentralized control, the decision making resides in the PEVs themselves. Each PEV thus requires a form of intelligence to autonomously optimize the charging process in terms of user preferences, cost, etc. García-Villalobos et al. (2014) also consider the vehicle-to-grid (V2G) concept to efficiently integrate PEVs into the grid. Through V2G technology EV owners can sell demandresponse services such as returning electricity to the grid while their cars are parked, allowing them to make revenue [79]. Additionally, Iversen et al. (2014) use a Markov chain to model driving patterns and integrate this while determining when and how much to charge [106]. Oliveira et al. (2013) use machine learning techniques, specifically artificial immune systems, to optimize PHEV charging [165].

Optimizing energy management of HEVs has received increasing attention. Murphey et al. (2012) propose a framework combining dynamic programming and machine learning to optimize energy management of an HEV [156]. The authors aim to minimize fuel consumption while maintaining performance by predicting roadway types, traffic congestion levels and driving trends to learn optimal energy settings, and reported fuel savings of 5-19\% in the second part of their study [157]. Finally, Moreno et al. (2006) use ultracapacitors and neural networks that learn an optimal control policy from driving cycles for energy management of HEVs [151].

\subsubsection{Anomaly detection}

Anomaly (or outlier) detection, aims to identify observations that indicate abnormal behavior, which could detect and help rectify incorrect or inefficient usage of a device to avoid losses. Devices can be repaired before the faulty behavior leads to fatal damage. The below discussion focusses on fault detection, one of the many applications of anomaly detection.

Machine learning techniques are used to model usage. Therefore, they can also be used to detect behavior deviating from the modelled normal patterns. Support vector machines (SVM) are used for fault detection and diagnosis (FDD) in chillers, improving energy efficiency and reducing maintenance costs [236]. Other applications for FDD include air-handling units [241], rotating machineries [175] and smart buildings [31]. For the latter, statistical pattern recognition techniques and artificial neural ensemble networks, coupled with outlier detection methods, are used to substantially reduce total building-energy demand by effectively detecting anomalous consumption, such as peaks in lighting and total electrical power when very few occupants are present. Early detection of gas or water leakage can thus be facilitated, avoiding excessive consumption and potentially dangerous situations. Other examples include anomalous consumption of cold rooms, HVAC systems, etc. Furthermore, swift identification of erroneous behavior can prevent fatal damage to appliances, extending their life time.

\subsubsection{Miscellanea}

In addition to the application domains detailed in previous sections is a non-exhaustive list of less visible but relevant application areas. Examples include carpooling, or other forms of shared mobility, that match users based on their mobility profiles [215]; intelligent coordinated traffic-light control that optimizes traffic flow for reduced traffic jams and thus emissions [122]; machine learning for optimizing elevator group control [44]; and smart manufacturing [149]. Currently existing are a small number of so-called smart cities, where IT is combined with infrastructure, architecture, everyday objects and even human bodies to tackle social, economic and ecological problems [214]. For example, in Barcelona, some neighborhood street lights are automatically extinguished when no activity is detected, and dumpsters keep track of their contents to optimize pick-up times [13].

\subsection{Effectiveness assessment}

Given the predictive nature of the applications discussed, prediction accuracy as an evaluation metric occurs in the majority of the reported studies. Since the aim is to use these predictions to reduce resource consumption, a percentage expressing potential savings is frequently reported. Although such a percentage is convenient for a straightforward comparison, Nguyen \& Aiello (2013) note that consumption or impact avoidance per functional unit is also desirable to assess the absolute relevance of the savings potential [163]. Few of the reported studies however contain life cycle assessment analysis results. Additionally, user comfort is a crucial evaluation criterion for successful intelligent systems [163]. Therefore, some studies introduce a discomfort measure such as 'miss time' in smart heating systems. Miss time then represents the fraction of time the user experienced inconvenience as the model falsely predicted user absence and thus did not turn on, e.g., heating [50]. Finally, many of the reported potential savings are based on simulations. Therefore, as noted for BECMS frameworks, it is essential that their feasibility is confirmed by evaluation in real-life experiments [163].

\subsubsection{Enabling effect}

Although these metrics provide some insight on the performance of specific applications, knowledge of the global effect of intelligent systems on the environment would be of interest. The Global eSustainability Institute (GeSI) has been studying the role of Information and Communications Technology (ICT) in sustainability. Their third report, \#SMARTer2030, reports that ICT can potentially enable a $20 \%(12 \mathrm{Gt})$ reduction of global $\mathrm{CO}_{2 \mathrm{e}}$ emissions by 2030, maintain 2015 emissions level and decouple economic growth from emissions growth [83]. Furthermore, the ICT sector's expected 2030 footprint is nearly 10 times lower 11.25 Gt or $1.97 \%$ ) than the avoided emissions. Also, ICT additionally offers other substantial environmental benefits, such as an increase of $30 \%$ in agricultural crop yields, a reduction of over 300 trillion liters of water consumption and reducing oil usage by 25 million barrels per year. These savings are a result of applications enabled by all forms of ICT. For this study, only the savings accomplished by smart systems are of interest. These are presented in Figure 9, resulting in a total $\mathrm{CO}_{2}$ abatement of 12.08 Gt. Although not all considered applications are autonomous/selflearning, it is clear that intelligent systems have a substantial environmental impact reduction potential.

\subsubsection{Rebound effect}


However, due to improved efficiency and the related cost reduction, end-users tend to adjust their habits which may result in increased usage of the systems under consideration. This phenomenon, known as the (direct, or first-order) rebound effect, reduces the potential savings. For example, a more fuel-efficient car results in a lower threshold for taking the car, and thus an increase in car usage, because of the reduced cost. This effect was also accounted for in the \#SMARTer 2030 report [83], as shown in Figure 9, reducing total abatement to $10.71 \mathrm{Gt}$. However, it is not clear whether the indirect rebound effect, which reflects the impact of re-spending the saved money on other goods and services, was also considered. The American Council for an Energy-Efficient Economy (ACEEE) estimates the extent of the indirect rebound effect to be approximately $11 \%$, although more profound studies are required [158]. However, even with this additional $11 \%$ savings reduction, smart systems still provide a substantial impact avoidance potential.

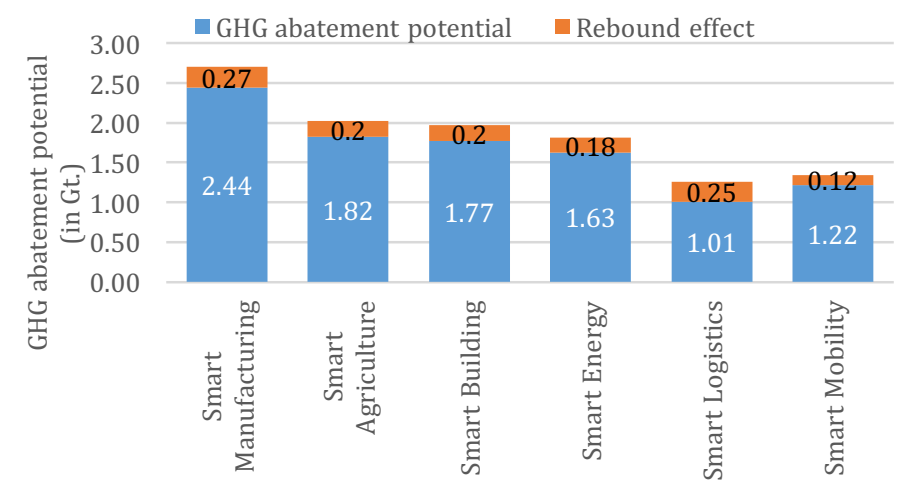

Figure 9: Greenhouse gas (GHG) abatement potential of smart systems (based on [83], Smart Mobility is the combination of Traffic Control Optimization and Connected Private Transportation)

Furthermore, Serna-Mansoux et al. (2014) developed a model to evaluate eco-oriented strategies, and account for dynamic product-user interaction [184]. Their model considers a mitigation rate, or an exponential decrease of the strategy's success to promote environmentally conscious behavior. This rate is especially applicable to feedback strategies, as messages have been shown to lose their persuasiveness over time [184]. In the case of autonomous smart systems, the relevance of the mitigation rate may be limited, as such systems aim to satisfy user comfort in addition to automatically making eco-oriented decisions. Indeed, for the example of heating, preheating a room in anticipation of an occupant's arrival will always increase impact as compared with an occupant switching on a heating system upon arrival. While optimized interactive control may show a better resource preservation performance, intelligent automatic control is likely to achieve substantial savings when compared to a preprogrammed static control. The degree to which improvements can be expected severely depend on the factors outlined in Section 3.1.

\subsection{Limitations of automated approaches}

The previous section highlighted the benefits of automated approaches for impact minimization. However, several limitations have also been identified and are discussed next.

For the applications to automatically minimize consumption and satisfy user preferences, they must gather relevant data and learn from them. Therefore, in some cases, additional devices, e.g., sensors, must be installed. Additionally, the more data are required to facilitate accurate predictions, the greater the delay in effectively using the system. The structure of the data constitutes another limitation. No matter how advanced the employed modeling technique, it cannot identify meaningful patterns nor accurately predict usage based on data reflecting random or non- systematic usage. Also, storage of the data can impose challenges. Storing a high-resolution data set locally can cause issues concerning memory capacity. Cloud storage on the other hand creates privacy concerns and poses a security risk as hackers might be able to intercept (potentially sensitive) data, e.g., embedded occupancy information in self-learning heating systems. Next, most techniques or solutions are application specific. Müller (2004) summarizes the situation rather well in, "There does not seem to be a system that learns quickly, is highly accurate, is nearly domain independent, does this from few examples with literally no bias and delivers a user model that is understandable and contains breaking news about the characteristics of the user" [154].

\subsubsection{Interaction}

Several limitations have also been identified regarding user interaction. For example, Yang \& Newman (2013) concluded that there is a bidirectional inability of understanding between a user and a machine [237]. That is, the system fails to grasp user intent, and the user does not understand how the system works. Although their study was focused on Google's Nest thermostat, they believe that the identified problems reflect deeper challenges in intelligent home-system design. The authors provide suggestions to overcome the challenges, namely exception flagging, incidental intelligibility and constrained engagement. Exception flagging is a way for people to inform the system that their current behavior is exceptional and should not be remembered. Incidental intelligibility helps users understand how the system interprets and acts upon the input data by embedding interaction elements in the tasks users aim to accomplish. Lastly, constrained engagement aims to spur user engagement as the user has more knowledge about the current and future situation. User engagement should, however, be limited to avoid overwhelming the user. This constrained engagement could be facilitated by both an attractive and thoughtful design.

Another interaction-related limitation is that users tend to completely rely on the system. For example, in the case of smart occupancy sensors [81], which predict when lights could be switched off, people relied on the system to extinguish the lights. As a result, savings were reduced by about $30 \%$ as often lights were left on for too long.

\subsubsection{Discomfort}

Due to the complexity of human behavior and the environment, the prediction accuracy of applications will never be $100 \%$. As a result, the user could suffer a degree of discomfort. Therefore, many intelligent systems provide a means to control the trade-off between comfort and impact or cost.

Also, certain kinds of sensors, needed to gather data for the system, could be intrusive to the users and make the user feel uncomfortable. Examples of such sensors are cameras and wearables. Nguyen \& Aiello argues that in energy conservation applications, a limited loss in accuracy could be tolerated in favor of using simple, non-intrusive sensors [163].

However, user trust is based on the system's accuracy and the experienced inconvenience. System performance should be adequately high as otherwise users might lose their trust, disable the system and revert to a less resource-conserving static solution.

\subsubsection{Validation}

With respect to evaluation, the main limitations are the lack of large real-life public data sets, real-life experiments and benchmarks. Smart energy systems are a hot topic in research, which means that a large amount of relevant data has been collected. However, these datasets are rarely made public or shared among researchers. The availability of open datasets, 
benchmarks and informative evaluation metrics would be beneficial for the development and comparison of methods. Furthermore, Nguyen \& Aiello found that the majority of studies are currently based on simulations, possibly due to the complexity and cost of test setups [163]. Therefore, there is a vital need for real-life experiments to evaluate the true performance and achieved savings of the targeted applications.

\subsection{Outlook on automated impact minimization}

Ever cheaper and more powerful electronics, and the increasing number of connected devices (forming the IoT) aid in realizing and expanding the demonstrated potential of ICT towards automated impact minimization in system/product usage. Findings of \#SMARTer2030 show a cleaner, healthier and more prosperous ICT-enabled world [83]. Smart buildings and transportation systems will develop into smart cities. One major difference with the current situation is the user-centric nature of these systems, as users will be able to personalize and co-create services in accordance with their preferences [83]. Enforcing national and global emission targets, incentivizing ICT investments, encouraging sustainable ICT-enabled services through consumer's buying power, etc. will help accelerate the widespread adoption of more sustainable ICT solutions [83].

However, several issues are associated with this evolution and need to be addressed. User activity, behavior and the environmental context, are identified as major inputs in automation systems, especially in BECMS [163][153]. Ubiquitous sensing is required to gain this knowledge. Moreover, all energy intelligent systems require some monitoring and data processing. To this end, sensors and actuators must be installed. A widespread adoption of such systems can by itself cause environmental burdens, such as growing electronic waste streams [235]. Caution should also be taken with regard to the intrusiveness of the sensing setup and related privacy concerns. Transparency is necessary to tackle the privacy problem. According to new European privacy guidelines, users should at least be aware of the data that are being stored and for what these are used [13]. Furthermore, Mozer (2004) noted, technology will only be adopted if the perceived return outweighs the efforts required to understand the system [153]. A well-designed user interface is thus of the utmost importance. Again transparency could be advantageous. Indicating the learned behavior, preferences and making users aware of their consumption might enable additional savings.

Finally, minimizing resource consumption while satisfying user comfort remains a challenging problem considering the conflicting nature of these objectives. The proposed systems should be able to deal with the complexity of user behavior and infer accurate predictions from raw sensor data. Therefore, further research is required towards combining preferences in multi-user environments. Auquilla et al. (2016), and Salem \& Rauterberg (2004) provided some initial studies on this topic [10] [178]. Another ongoing challenge is the dynamic modelling of user needs and preferences. As user behavior and preferences evolve over time, the systems must be able to detect and adapt to these changes. De Bock et al. (2016a) presented an approach to deal with dynamic behavior for smart heating systems [50]. Again, it is essential that approaches are validated in real-life experiments. Developments on these challenges will improve the reliability of the envisaged systems and increase their sustainability potential.

\section{Case study: From information and feedback to automatic} control towards efficient truck driving

Scania trucks feature two systems that support efficient driving: 1) Scania Driver Support, a default feature on trucks that came into existence before 2) Scania's Cruise Control Active Prediction.

\subsection{Driver support using information and feedback}

Scania Driver Support (SDS) is a real-time system that gives a truck drivers feedback via the instrument cluster on how well they are controlling the truck. SDS continually analyses data from sensors in the truck, with the goal of assisting drivers to operate the truck as safely and efficiently as possible. Drivers selectively receive recommendations while driving, as well as accumulated assessment of their driving style. Four aspects of driving performance are measured and evaluated: 1) hill driving, i.e., how the accelerator pedal and vehicle's momentum are utilized; 2) anticipation, which consists of heavy accelerations and decelerations, as well as the intervals between accelerating and braking, which are used to assess how well the driver anticipates different situations; 3) brake use, i.e., the frequency and harshness of brake applications, as well as efficient use of the auxiliary brake system; and 4) choice of gears, i.e., how gears are selected and shifted to match the engine load and terrain. When driving in hybrid mode, another category for brake use is adopted as well. Figure 10 shows example feedback given to a driver based on SDS analysis. When CCAP is active, feedback is given only for category 4) choice of gears. Besides the categories, other tips are shown, e.g., regarding revolutions per minute (RPM).

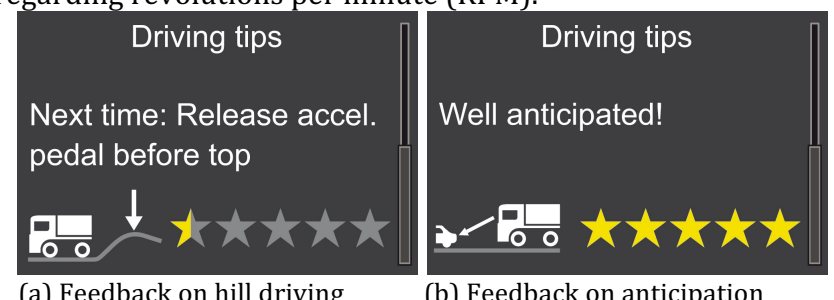

(a) Feedback on hill driving

(b) Feedback on anticipation

Figure 10: Example feedback displayed in instrument cluster (Scania)

SDS builds upon the skills acquired during driver training courses by truck manufacturer Scania, and using SDS, extends the effects of the courses. Scania's own tests have shown that its training concept, i.e., combined training with SDS and regular coaching based on evaluation reports of the driver's performance compared with other drivers, can reduce fuel consumption as well as its variation (indicating a more consistent driving style). According to Scania, most drivers who have taken the training courses seem to appreciate the real-time feedback of SDS.

\subsection{Driver support using automation}

Cruise Control Active Prediction (CCAP) is an automatic controller that Scania has commercially sold and installed on its own trucks since 2012. CCAP enables automatic adjustment of a truck's speed and gear based on topographical data, its performance mode concerning fuel efficiency (standard mode versus economy mode) pre-selected by the driver, and product data including vehicle mass, wheel radius, engine torque and gear ratio. The key technology lies in the controller's use of a topographical map, especially data concerning the inclination of upcoming roads.

CCAP uses a Global Positioning System (GPS) to determine the current vehicle position on the truck route, and predict near-future topography based on road data (available for about 95\% of the main and secondary roads in western and central Europe) to proactively control the speed of the vehicle in a fuel-efficient way. Prior to driving, a truck driver sets two speeds for the CCAP, a cruising speed for flat reads, (e.g. $85 \mathrm{~km} / \mathrm{h}$ ), and a downhill speed (e.g. $89 \mathrm{~km} / \mathrm{h}$ ) for descents.

Typically, CCAP reduces the speed before a descent, where the vehicle will accelerate by its own weight, to minimize driving resistance and avoid unnecessary braking (see Figure 11). In this way, fuel is saved compared to a speed-control system that does not use topographical data. CCAP also aims to use a high gear during speed reduction to minimize engine frictional losses. On the 
other hand, during ascent, CCAP increases the speed before the uphill portion, leading to reduced driving time, but also increased fuel consumption, i.e., the added fuel consumption is often smaller than the fuel savings gained from the descent [100].

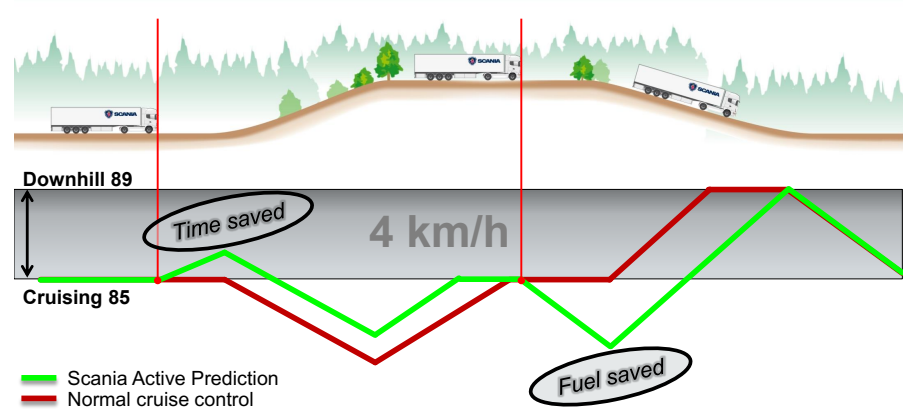

Figure 11: A comparison between CCAP and a traditional system (Scania)

Compared to a traditional cruise controller, CCAP better controls the vehicle speed with respect to fuel consumption, resulting in on average, about $3 \%$ decrease in energy consumption during the use phase without increasing the overall travel time in the standard mode. According to Hellström et al. (2009), in economy mode, fuel consumption is decreased even more, but the travel time is increased [100]. Fuel consumption is obviously road-dependent; for example, Eriksson et al. (2016) is formulating a benchmark problem for fuel-efficiency determination in the long-haul truck sector taking into account this factor [66]. On undulating roads, where a vehicle will often accelerate or decelerate by its own weight, it is harder to drive in a fuel-efficient manner. According to Scania, on such roads, CCAP helps the driver to save more than $3 \%$ on fuel consumption since there are more opportunities to optimize the speed. On a completely flat road, no such opportunity is given to CCAP, leading to no change in energy consumption. Regarding benefits and drivers' skills, less experienced drivers are likely to benefit more and also have an opportunity to learn an economical driving style in the process. This presents possibilities to change user behavior, although no concrete data are available in this respect yet. Highly-skilled drivers benefit less, especially on well-known routes, but on unknown routes, and especially in the dark or in bad weather conditions, CCAP is more likely to help them save fuel.

Because CCAP is used in real life, some practical features are also implemented. For instance, before a hill, the speed is allowed a maximum $6 \%$ drop from the set cruising speed to decrease the risk of collision with a following car. In economy mode, the maximum drop is $12 \%$. Furthermore, the road data are stored in the Scania Communicator, which continuously collects and transmits driver and vehicle data as well as positioning to the Scania Fleet Management portal. This creates possibilities to further improve fuel efficiency by analyzing a large amount of stored data. Concerning users, there is resistance by some drivers for using CCAP; reasons for which include a desire to minimize driving time. Therefore, drivers' mindsets on acceptance of a system's automatic control are also relevant.

In summary, CCAP realizes automatic control of a product by software based on the product's anticipated usage, its user preference, and the product's data.

\section{Summary and outlook}

One frequently described obstacle to PEB is that individuals question the impact their actions may have on seemingly overwhelming environmental problems [204]. At the same time, designers and engineers may underestimate the tremendous effect on consumer behavior and resource consumption that even subtle features of products play. As individuals, engineers and designers then, have a disproportionate opportunity, and thus responsibility, to properly design and realize products and systems to most effectively minimize resource consumption during the use phase of products.

As the content of the present paper reveals, realizing PEBenabling products is by necessity a multi-disciplinary endeavor that requires at least an appreciation of the other fields involved. Uiterkamp \& Vlek (2007) note that "isolated monodisciplinary approaches or a noninteracting set of separate disciplines are insufficient for an adequate understanding of rather complex societal problems, of which (un)sustainable development is an urgent example" [221].

This paper presented several dimensions through which to view design for reduced resource consumption during the use phase of products. The two major parts of the paper correspond to two different approaches: convincing users to adopt the desired behavior, or having technology perform the desired behavior for people. The two approaches also occupy different parts of a commonly used range that describe the extent a human or product is in control of the desired behavior. Each point along this range offers advantages as well as limitations. In the end, it is up to the designer to determine the most appropriate point(s) in the range, for a particular goal. Below are both summarized and additional aspects to consider when making this determination.

\subsection{Information and Feedback}

Information and feedback dominate existing PEB interventions, perhaps because they are the easiest and cheapest to implement. Certainly such interventions can be a first step, and even informational signs can benefit from being well-designed.

However, researchers have long noted that information and feedback are effective only if they help users achieve preexisting goals [139]. That is, information and feedback on resource consumption does little for those uninterested in resource conservation, just as nutritional labeling of food does little for those uninterested in healthier eating.

Shove \& Warde highlight the shifting standards and norms in expectations of cleanliness, comfort and convenience [187]. Much consumption behavior has been driven by commercial interests, i.e., advertising that exploits psychology to prescribe what people desire and require. Future information-based interventions can no longer take the form of dry warnings from government and scientists, but must exploit the same advertising forces that drove overconsumption in the first place. Thorpe (2010) noted that consumer goods have become symbolic resources. Profit-seeking commercial interests control these symbols, and without providing alternatives "the challenge of sustainable consumption lies well beyond the reach of typical informed choice models that environmentalists have tended to pursue" [210]. Noppers et al. (2014) suggest that consumers may not recognize the significance of symbolic motives for their adopting sustainable innovations [162]. However, as fewer commercial interests benefit from curtailed consumption, the costs of such advertising may have to be borne by the public sector, and be consistent with resourceconserving policies.

\subsection{Enabling and encouraging}

While behavior is believed to follow attitude, a change in behavior may also lead to a change in attitude, perhaps to reduce cognitive dissonance. Cognitive dissonance refers to the state of having inconsistent beliefs, or performing actions that contradict beliefs [69]. In a meta-analysis of 87 published reports containing 253 experimental treatments, Osbaldiston \& Schott (2012) identified that treatments incorporating cognitive dissonance, amongst other factors, showed the largest effect in resource 
conservation [166]. Thus, persuading users to perform a desired behavior, even if such behavior contradicts their beliefs, may have benefits over simply performing the behavior for them.

Cognitive heuristics are unconscious rules utilized to enhance the efficiency of information processing and are possible antecedents of cognitive biases, which may lead to perceptual distortion, inaccurate judgment and illogical interpretation. Cialdini (1984) identified many strategies (reciprocity, commitment and consistency, social proof, authority, liking and scarcity) that can be linked to cognitive biases [38]. These strategies have formed the basis for many PEB interventions. Lockton et al. (2010) also use a number of cognitive biases in the Design-with-Intent framework [133]. Discretization of resources, abstracted from studying Old Order Mennonites, and incorporated as shown in Figure 3, may resonate with many people because it triggers a specific cognitive bias. The unit bias has been observed in food consumption, as people generally tend to consume quantities suggested by unit sizes. In addition, the pre-filled shower tank may contribute to norm-setting of water quantity.

A related approach is to physically change defaults. For example, single-handle faucets, where lifting the handle in a symmetric default manner produces warm water, should be changed such that the default manipulation yields cold water. Where possible, an ability to opt out of defaults should be possible without too much difficulty, as products that are inappropriately forceful are likely to be disabled. For the faucet example, this could be a cue to move the handle away from the default symmetric maneuver in order to obtain warm water.

Much existing work on PEB involves application of social psychology. Future interventions could investigate the increased application of cognitive psychology. For example, behavioral economists Thaler and Sunstein (2008) describe as "nudges" examples of physical affordances that change behavior [208]. One nudge involves painting white stripes more closely together on a dangerous portion of curved road. Such stripes give the sensation that driving speed is increasing, thereby urging drivers to slow down. Vicente (2006) identified another nudge that involves placing stickers that depict flies in urinals, which significantly improved aim and thus reduced spillage [227]. Identifying other triggers of behavior relevant to PEB will complement the large amount of existing work that focuses on social psychology.

\subsection{Forcing and automation}

While automation has demonstrated clear benefits for resource conservation, it also has surprising limitations. For example, lack of standardization may cause users to neglect performing the required action, e.g., turning off a manual faucet, when they have become accustomed to such actions being automated by sensoroperated faucets. Standardization is not just a problem that involves automation. Duffy \& Verges (2009) found that in public settings, specialized recycling container lids (compared with no lids) increased recycling rate by $34 \%$, suggesting that perceptual affordances of specialized container lids improve recycling compliance. However, adaptive cognition is presented as a possible mechanism. That is, because most public recycling containers have specialized lids, people may associate receptacles without specialized lid as for discarding trash, whereas any receptacle with a specialized lid is for discarding recyclables [59].

Faulty sensors not only waste resources, e.g., auto-flush toilets triggered to flush multiple times instead of once, but may also inspire users towards creative ways of overriding such automation. While identifying technology's four roles in resource conservation, Midden et al. (2007) note that "modern systems gain intelligence at a dazzling pace, but they risk a loss of transparency and predictability at the same time. This signifies the issue of user acceptance and people's willingness to trust and delegate control to such systems" [145]. Lee's (2006) comprehensive summary of the pitfalls of automation with respect to human factors and ergonomics may have particular relevance to automation for PEB. Information about the pitfalls is derived from the many decades of experience of human-factors researchers with automation in various environments. Pitfalls identified include: out-of the-loop unfamiliarity, clumsy automation, automation-induced errors, inappropriate trust (misuse, disuse and complacency), behavioral adaption, and interaction between automation problems [125]. Again, an option must be provided to opt out of such automation, especially when it fails to meet user needs in critical situations.

While in cases where users are not motivated for PEB, the possible effects of automation can limit impact considerably. However, in the case of well-motivated users, the benefits can indeed be non-existent or even negative. Pre-heating a dwelling in anticipation of the arrival of an inhabitant may add to the comfort level, but will never help to preserve energy in comparison with a motivated user switching on a heating system upon arrival and anticipating departure by an early switch off of the same.

\subsection{Outlook}

The need for further studies that can help to optimize the flexible choice between user-driven control in the case of well-motivated end-users of systems, and automated resource preservation strategies in the case of negligent behavior is acknowledged. An optimal combination of both strategies is likely to exceed the performance of the individual approaches, but requires assessment of the performance achieved by the user and comparing this with the use of well-optimized automated strategies.

Designers must achieve a delicate balance between nudging consumers towards the desired resource-conserving behavior, and the perception that resource-conserving behavior is still a choice, not unlike some safety-related behavior. An obvious but non-pervasive approach towards this goal is to design products such that the easiest (functionally, cognitively, ergonomically and aesthetically) options are those that support PEB.

This paper suggests that designers should also consider the range of factors from those that are internal to people, e.g., values and beliefs, to those that are external to them, e.g., physical environment, including available products. Social scientists believe that automation without the user's explicit choice towards resource conservation will neither instill nor sustain values that lead users to pursue or persist in sustainable behavior. For example, Evans et al. (2013) support the possibility of "spillover" from one PEB to another by appealing to self-transcendent rather than self-interested motives [68].

However, to supplement interventions that emphasize selftranscendence, additional values that support PEB must be identified and drawn upon to engage those who have little or no self-transcendent tendencies. Whitmarsh (2009) and Gifford \& Sussman (2012) note that people often perform sustainable behavior for reasons unrelated to the environment [231][86]. Corral-Verdugo et al. (2015) found that sustainable behavior is strongly related to values of frugality and equitable behavior, in addition to pro-ecological and altruistic values [42]. Srivastava \& Shu (2013a) noted that resource-conserving lead users, Old Order Mennonites value self-sufficiency, but have low altruism towards those outside of their community [193].

Observing or studying other lead users in PEB may be used to uncover further strategies that support PEB, which could form the basis for new products. For example, an often reported but counter-intuitive strategy used by United Parcel Service drivers to reduce fuel consumption involves minimizing left-hand turns [140]. Mostly to increase safety, Google's navigation app Waze has a feature to help drivers avoid left-hand turns at difficult intersections [119]. Another example involves the "Dutch reach", i.e., drivers opening their car door using their far arm, thereby 
turning and checking for cyclists before they collide into their opened door. A website promoting this practice suggests that drivers tie a ribbon on the door handle to remind them to do this (www.dutchreach.org). Product designers could redesign the door handle such that it is more ergonomic to use the far hand to open the door. Ideally such a handle could still be used by those who physically cannot use their far hand, but would be guided in some other way to check for cyclists before opening the door.

Much existing work on PEB relies on surveys and thus selfreported behavior. Not surprisingly, Huffman et al. (2014) note that self-reported and observed recycling behavior are correlated, but not strongly [105], while other researchers are reviewing the validity of self-report measures [117]. The realization of more products to support PEB should therefore be evaluated through observation, and not self reported behavior.

Product designers are in a unique position to catalyze PEB. By creating more successful PEB-supporting products, designers add to existing interventions towards resource-conserving standards. It is widely accepted that personal behavior is significantly affected by others' behaviors [7]. By using product design to increase the number of people who take part in PEB beyond a critical mass, other people will follow, further increasing the proportion of participation needed to justify corresponding shifts in infrastructure, possibly shape public policy, and thus set new norms in consumptive behavior.

\section{Acknowledgments}

The authors thank Linda Steg, Eric Lutters, Daniel Brissaud and Tullio Tolio, for their very helpful comments on this paper. LH Shu and J Srivastava acknowledge the financial support of the Natural Science and Engineering Research Council of Canada (NSERC), and the Hanse-Wissenschaftskolleg (HWK) of Germany, where this paper was finally compiled. J Duflou and Y De Bock acknowledge the financial support received under the Flemish government PERPETUAL IWT/VLAIO SBO project. T Sakao acknowledges Scania personnel Mikael Hedlind, Ph.D., Erik Holma and Johan Björkegren for the development of the case study.

\section{References}

[1] Abe R, Taoka H, McQuilkin D (2011) Digital grid: Communicative electrical grids of the future. IEEE Transactions on Smart Grid 2/2:399-410.

[2] Abrahamse W, Steg L, Vlek C, Rothengatter T (2005) A review of intervention studies aimed at household energy conservation, J Environmental Psychology. 25/3:273-291.

[3] Ajzen I (1991) The Theory of Planned Behavior. Organization Behavior and Human Decision Processes, 50/2:179-211.

[4] Akaka MA, Vargo SL (2015) Extending the context of service: from encounters to ecosystems. J Services Marketing, 29/6-7:453-462.

[5] Akrich M (1992) The de-scription of technical objects. In Shaping Technology, Building Society (Bijker WE, Law J, eds.), MIT Press, pp. 205-225.

[6] Amft O, Medland R, Foth M, Petkov P, Abreu J, Pereira FC, Johnson P, Brewer R, Pierce J, Paulos E (2011) Smart energy systems. IEEE Pervasive Computing 10/1:63-65.

[7] Ando K, Ohnuma S, Chang E (2007) Comparing Normative Influences as Determinants of Environmentally Conscious Behaviors b/w USA \& Japan. Asian J Social Psychology. 10:171-178.

[8] Arpan LM, Barooah P, Subramany R (2015) The Role of Values, Moral Norms, and Descriptive Norms in Building Occupant Responses to an Energy-Efficiency Pilot Program and to Framing of Related Messages. Applied Environmental Education \& Communication 14:23-32.

[9] Augusto JC (2007) Ambient intelligence: the confluence of ubiquitous /pervasive computing and artificial intelligence. Intelligent Computing Everywhere, pp. 213-234.

[10] Auquilla A, De Bock Y, Nowé A, Duflou JR (2016) Combining Occupancy User Profiles in a Multi-user Environment: An Academic Office Case Study. 12th Int. Conf. Intelligent Environments (IE), pp. 186-189.

[11] Aztiria A, Izaguirre A, Augusto JC (2010) Learning patterns in ambient intelligence environments: a survey. Artificial Intelligence Review 34/1:35-51.

[12] Bailey JO, Bailenson JN, Flora J, Armel KC, Voelker D, Reeves B (2015) The impact of vivid messages on reducing energy consumption related to hot water use. Environment and Behavior 47/5:570-592.

[13] Ballon P (2016) Smart Cities: Hoe technologie onze steden leefbaar houdt en slimmer maakt. Lannoo Campus, Leuven, Belgium, 224p.
[14] Bamberg S, Schmidt P (2003) Incentives, morality, or habit? Predicting students' car use for university routes with the models of Ajzen, Schwartz and Triandis. Environment and Behavior 35:2/264-285.

[15] Bamberg S (2013) Applying the stage model of self-regulated behavioral change in a car use reduction intervention. J Environmental Psychology 33:68-75.

[16] Bandura A (1977) Self-efficacy: Toward a unifying theory of behavioral change. Psychological Review 84/2:191-215.

[17] Bandura A (1986) Social foundations of thought and action: A social cognitive theory. Prentice-Hall series in social learning theory. Englewood Cliffs, NJ, US.

[18] Barbato A, Borsani L, Capone A, Melzi S (2009) Home energy saving through a user profiling system based on wireless sensors. Proc. 1st ACM Workshop on Embedded Sensing Systems for Energy-Efficiency in Buildings, pp. 49-54.

[19] Barbato A, Capone A, Rodolfi M, Tagliaferri D (2011) Forecasting the usage of household appliances through power meter sensors for demand management in the smart grid. IEEE Int. Conf. Smart Grid Communications, pp. 404-409.

[20] Basu K, Hawarah L, Arghira N, Joumaa H, Ploix S (2013) A prediction system for home appliance usage. Energy and Buildings, 67:668-679.

[21] Beier J, Thiede S, Herrmann C (2017) Energy flexibility of manufacturing systems for variable renewable energy supply integration: Real-time control method and simulation. Journal of Cleaner Production 141: 648-661.

[22] Ben-Nakhi AE, Mahmoud MA (2004) Cooling load prediction for buildings using general regression neural networks. Energy Conversion and Management 45/13:2127-2141.

[23] Benzoni N, Telenko C (2016) A review of intervention studies aimed at domestic water conservation, HCI Int. Conf., July 20-22, Toronto, Canada.

[24] Berkhout PHG, Muskens JC, Velthuijsen JW (2000) Defining the rebound effect. Energy policy 28/6:425-432

[25] Bhamra T, Lilley D, Tang T (2011) Design for sustainable behaviour: Using products to change consumer behaviour. The Design Journal. 14/4:427-445.

[26] Bockarjova M, Steg L (2014) Can Protection Motivation Theory predict proenvironmental behavior? Explaining the adoption of electric vehicles in the Netherlands. Global Environmental Change 28:276-288.

[27] Bratt C, Stern PC, Matthies E, Nenseth B (2015) Home, car use, and vacation: The structure of environmentally significant individual behavior. Environment and Behavior 47/4:436-473.

[28] Brown D, Blessing L (2005) The relationship between function and affordance. Proc. ASME Int. Design Engineering Technical Conf., Sept. 24-28, Long Beach, CA, USA, DETC2005-85017.

[29] Brynjarsdottir H, Håkansson M, Pierce J, Baumer E, DiSalvo C, Sengers P (2012) Sustainably unpersuaded: How Persuasion Narrows Our Vision of Sustainability. Proc. ACM Annu. Conf. Hum. Factors Comput. Syst. CHI, p. 947.

[30] Burton J Easingwood C (2006) A positioning typology of consumers perceptions of the benefits offered by successful service brands. J Retailing and Consumer Services 13/5:301-316.

[31] Capozzoli A, Lauro F, Khan I (2015) Fault detection analysis using data mining techniques for a cluster of smart office buildings. Expert Systems with Applications 42/9:4324-4338.

[32] Cardenas-Tamayo RA, García-Macías JA, Miller Tm, Rich P, Davis J, Albesa J, Gasulla M, Higuera J, Penella MT, Garcia J, Fernández-Montes A (2009) Pervasive computing approaches to environmental sustainability. IEEE Pervasive Computing 8/1:54-57.

[33] Chandra A, Anderson G, Melkote S, Gao W, Haitjema H, Wegener K (2014) Role of surfaces and interfaces in solar cell manufacturing. CIRP Annals 63/2:797819.

[34] Chang C, Verhaegen PA, Duflou JR (2013) Finding days-of-week representation for intelligent machine usage profiling. J Industrial and Intelligent Information 1/3:148-154.

[35] Chang C, Verhaegen PA, Duflou JR (2014) A comparison of classifiers for intelligent machine usage prediction. IEEE Int. Conf. Intelligent Environments, pp. 198-201.

[36] Christie LH (2010) Understanding New Zealand Homeowners Apparent Reluctance to Adopt Housing-Sustainability Innovations. PhD Dissertation, Victoria Univ. Wellington.

[37] Christophe F, Bernard A, Coatanéa É (2010) RFBS: A model for knowledge representation of conceptual design, CIRP Annals 59/1:155-158.

[38] Cialdini R (1984) Influence: The Psychology of Persuasion. William Morrow, NY.

[39] Cialdini RB, Reno RR, Kallgren CA (1990) A Focus Theory of Normative Conduct: Recycling the Concept of Norms to Reduce Littering in Public Places. Journal of Personality and Social Psychology 58/6:1015-1026.

[40] Cor E, Domingo L, Brissaud D, Zwolinsk P (2014) A protocol to perform usage oriented ecodesign. CIRP Annals 63/1:169-172.

[41] Corral-Verdugo V, Frias-Armenta M, Pérez-Urias F, Orduña-Cabrera V, Espinoza-Gallego N (2002) Residential water consumption, motivation for conserving water and the continuing tragedy of the commons. Environmental Management 30/4:527-535.

[42] Corral-Verdugo V, Tapia-Fonllem C, Ortiz-Valdez A (2015) On the relationship between character strengths and sustainable behavior. Environment and Behavior. 47/8:877-901.

[43] Coskun A, Zimmerman J, Erbug C, (2015) Promoting sustainability through behavior change: A review. Design Studies. 41/183-204.

[44] Crites RH, Barto AG (1998) Elevator group control using multiple reinforcement learning agents. Machine Learning 33/2-3:235-262.

[45] Csikszentmihalyi M, Csikszentmihalyi IS, eds. (1988). Optimal Experience: Psychological studies of flow in consciousness, Cambridge University Press.

[46] Daae JZ, Boks C (2011) Reinforcing preliminary design strategy selection guidelines with insight from Fogg's behavior grid, Proc. 6th Int. Conf. Persuasive 
Technology: Persuasive Technology and Design: Enhancing Sustainability and Health, Columbus, pp. 21-26.

[47] Daae J, Boks C (2014) Dimensions of behavior change. J Design Research 12/3:145-172.

[48] Daae J, Boks C (2015) A classification of user research methods for design for sustainable behaviour. J Cleaner Production 106:680-689.

[49] Davoudi S, Dilley L, Crawford J (2014) Energy consumption behavior: rational or habitual? disP-The Planning Review, 50/3:11-19.

[50] De Bock Y, Auquilla A, Kellens K, Vandevenne D, Nowé A, Duflou J (2016a) User adapting system design for improved energy efficiency during the use phase of products: Case study of an occupancy-driven, self-learning thermostat. Sustainability through innovation in product life cycle design. Springer 883-98.

[51] De Bock Y, Auquilla A, Kellens K, Nowé A, Duflou J (2016b) Intelligent occupancy-driven thermostat by dynamic user profiling. Proc. Electronics Goes Green 2016+ Berlin

[52] De Groot JIM, Steg L (2008) Value orientations to explain environmental attitudes and beliefs: How to measure egoistic, altruistic and biospheric value orientations. Environment and Behavior 40/3: 330-354.

[53] De Hauwere YM, Van Moffaert K, Verhaegen PA, Nowé A (2013) Networks as a tool to save energy while keeping up general user comfort in buildings. $19^{\text {th }}$ IEEE Workshop on Local \& Metropolitan Area Networks, pp. 1-6.

[54] Deci EL, Ryan RM (2000). The "what" and "why" of goal pursuits: Human needs and self-determination of behavior. Psychological Inquiry 11:227-268.

[55] DiSalvo C, Sengers P, Brynjarsdóttir H (2010) Mapping the landscape of sustainable HCI. Proc. SIGCHI Conf. Human Factors in Computing Systems. ACM, pp. $1975-1984$

[56] Doran R, Larsen S (2016) The relative importance of social and personal norms in explaining intentions to choose eco-friendly travel options. Int. J. Tourism Research 18: 159-166.

[57] Dori D, Shpitalni M (2005) Mapping knowledge about product lifecycle engineering for ontology construction via object-process methodology, CIRP Annals 54/1:117-122.

[58] Dornfeld DA (2014) Moving towards green and sustainable manufacturing. Int. J Precision Engineering and Manufacturing-Green Technology 1/1:63-66.

[59] Duffy S, Verges M (2009) It matters a hole lot: Perceptual affordances of waste containers influence recycling compliance. Environment and Behavior 41/5:741-749.

[60] Duflou J, Auquilla A, De Bock Y, Nowé A, Kellens K (2016) Impact reduction potential by usage anticipation under comfort trade-off conditions. CIRP Annals 65/1:33-36.

[61] Dunlap RE, Van Liere KD (1978) The "New Environmental Paradigm": A Proposed Measuring Instrument and Preliminary Results. J Environmental Education 9:10-19.

[62] EIA (2009) Residential Energy Consumption Survey. Energy Information Administration, U.S. Department of Energy.

[63] EIA (2012) Commercial Buildings Energy Consumption Survey. Energy Information Administration, U.S. Department of Energy.

[64] Elias E, Dekoninck E, Culley S (2008) Assessing user behaviour for changes in the design of energy using domestic products. Proc. IEEE Int. Symp. Electronics and the Environment, 19 -22 May.

[65] Erickson VL, Achleitner S, Cerpa AE (2013) POEM: Power-efficient occupancybased energy management system. ACM/IEEE Int. Conf. Information Processing in Sensor Networks (IPSN). IEEE, pp. 203-216.

[66] Eriksson VL, Larsson A, Thomasson A (2016) The AAC2016 benchmark - lookahead control of heavy duty trucks on open roads. 8th IFAC Symp. Advances in Automotive Control, pp. 121-127. Kolmården, Sweden, 20-23 June 2016.

[67] Evans D (2011) Beyond the throwaway society: ordinary domestic practice and a sociological approach to household food waste. Sociology 46/1:41-56.

[68] Evans L, Maio, GR, Corner A, Hodgetts CJ, Ahmed S, Hahn U (2013) Self-interest and pro-environmental behavior. Nature Climate Change 3/122-125.

[69] Festinger L, Carlsmith JM (1959) Cognitive consequences of forced compliance. J Abnormal and Social Psychology 58:203-210.

[70] Fischer JE, Ramchurn SD, Osborne M, Parson O, Huynh TD, Alam M, Pantidi N, Moran S, Bachour K, Reece S, Costanza E (2013) Recommending energy tariffs and load shifting based on smart household usage profiling. Proc. 2013 Int. Conf. Intelligent user interfaces. ACM, pp. 383-394.

[71] Fishbein M, I Ajzen (1975) Belief, Attitude, Intention, and Behavior: An Introduction to Theory and Research. Reading, MA: Addison-Wesley.

[72] Farmar-Bowers Q, Lane R (2006) Understanding farmers decision systems that relate to land use, School of Global Studies, Social Sciences and Planning, Report, RMIT University, Melbourne, Australia.

[73] Fogg BJ (2003) Persuasive Technology: Using Computers to Change What We Think and Do. Morgan Kaufmann Publishers, San Francisco, CA

[74] Fogg BJ (2009) A behavior model for persuasive design. Proc. Persuasive'09, April 26-29, Claremont, CA, USA.

[75] Fogg BJ, Hreha J (2010) Behavior wizard: a method for matching target behaviors with solutions, Proc. 5th Int. Conf. Persuasive Technology, Copenhagen, pp.117-131.

[76] Framling K, McFarlane D (2009) Editorial, Computers in Industry (Special issue on Intelligent Products) 60/3:135-136.

[77] Frye A, Goraczko M, Liu J, Prodhan A, Whitehouse K (2013) Circulo: Saving energy with just-in-time hot water recirculation. Proc. 5th ACM Workshop on Embedded Systems for Energy-Efficient Buildings. ACM, pp. 1-8.

[78] Fujii S, Gärling T (2003) Development of script-based travel mode choice after forced change. Transportation Research Part F 6:117-124.
[79] García-Villalobos J, Zamora I, San Martín JI, Asensio FJ, Aperribay V (2014) Plugin electric vehicles in electric distribution networks: A review of smart charging approaches. Renewable and Sustainable Energy Reviews 38:717-731.

[80] Gardner GT, Stern PC (2008) The short list: The most effective actions U.S. households can take to curb climate change. Environment: Science and Policy for Sustainable Development 50/5:12-25.

[81] Garg V, Bansal NK (2000) Smart occupancy sensors to reduce energy consumption. Energy and Buildings 32/1:81-87.

[82] Gaver WW (1991). Technology affordances, Proc. SIGCHI Conf. Human factors in computing systems, New Orleans, LA, April 27 - May 02.

[83] GeSI (2015) \# SMARTer2030: ICT solutions for 21st century challenges. The Global eSustainability Initiative (GeSI), Brussels, Brussels-Capital Region, Belgium, Tech. Rep. [Online] Available: http://www.smarter2030.org

[84] Gharavi H, Ghafurian R, eds. (2011) Smart grid: The electric energy system of the future. IEEE, Vol. 90 .

[85] Gibson J (1977) The theory of affordances. In Perceiving, Acting, and Knowing: Toward an Ecological Psychology (Shaw F, Bransford J, eds.) Hillsdale, NJ: Lawrence Erlbaum. pp. 67-82.

[86] Gifford R, Sussman R (2012) Environmental attitudes, in The Oxford Handbook of Environmental and Conservation Psychology, Ed: SD Clayton. Oxford University Press. DOI: 10.1093/oxfordhb/9780199733026.013.0004

[87] Gifford R, Nilsson A (2014) Personal and social factors that influence proenvironmental concern and behavior: a review. Int. J Psychology 49/3:141-157.

[88] Golan A, Fenko A (2015) Toward a sustainable faucet design: Effects of sound and vision on perception of running water. Environment and Behavior 47/1:85101.

[89] Goucher-Lambert K, Cagan J (2014) The impact of sustainability on consumer preference judgments of product attributes. Proc. ASME Int. Design Engineering Technical Confs. Aug. 17-20, Buffalo, NY, USA, DETC2014-34739.

[90] Goucher-Lambert K, Moss J, Cagan J (2017) Inside the mind: Using neuroimaging to understand moral product preference judgments involving sustainability. J Mechanical Design 139:041103-1

[91] Greiner R, Lankester A, Patterson L (2007) Incentives to enhance the adoption of 'best management practices' by landholders: Achieving water quality improvements in the Burdekin River Catchment. Report, River Consulting, Townsville, Australia.

[92] Greiner R, Gregg D (2011) Farmers' intrinsic motivations, barriers to the adoption of conservation practices and effectiveness of policy instruments: Empirical evidence from northern Australia. Land Use Policy 28/1:257-265.

[93] Gromet DM, Kunreuther H, Larrick RP (2013) Political ideology affects energyefficiency attitudes and choices. Proc. National Academy of Sciences 110/23:9314-9319.

[94] Gupta M, Intille SS, Larson K (2009) Adding GPS-control to traditional thermostats: An exploration of potential energy savings and design challenges. Int. Conf. Pervasive Computing, pp. 95-114.

[95] Harms R, Fleschutz T, Seliger G (2010) Life cycle management of production facilities using semantic web technologies. CIRP Annals 59/1:45-48.

[96] Hauschild M, Wenzel H, Alting L (1999) Life cycle design - a route to the sustainable industrial culture? CIRP Annals 48/1:393-396.

[97] Hauschild MZ, Jeswiet J, Alting L (2004) Design for environment: Do we get the focus right? CIRP Annals 53/1:1-4.

[98] Hauschild MZ, Jeswiet J, Alting L (2005) From Life Cycle Assessment to sustainable production: Status and perspectives CIRP Annals 54/2:535-555.

[99] Hazas M, Friday A, Scott J (2011) Look back before leaping forward: Four decades of domestic energy inquiry. IEEE pervasive Computing 10:13-19.

[100] Hellström E, Ivarsson M, Åslund J, Nielsen L (2009) Look-ahead control for heavy trucks to minimize trip time and fuel consumption. Control Engineering Practice 17/2:245-254.

[101] Herring H (2006) Energy efficiency - a critical view. Energy 31/1:10-20.

[102] Hirose Y (1994) Determinants of pro-environmental behavior. The Japanese Journal of Social Psychology 10/1:44-55.

[103] Hirsh JB, Kang SK, Bodenhausen GV (2012) Personalized persuasion: Tailoring persuasive appeals to recipient personality traits. Psychological Science 23: 578-581.

[104] Hirsh JB (2014) Environmental sustainability and national personality. J Environmental Psychology 38:233-240.

[105] Huffman AH, Van Der Werff BR, Henning JB, Watrous-Rodriguez K (2014) When do recycling attitudes predict recycling? An investigation of self-reported versus observed behavior. J Environmental Psychology 38:262-270.

[106] Iversen EB, Morales JM, Madsen H (2014) Optimal charging of an electric vehicle using a Markov decision process. Applied Energy 123:1-12.

[107] Janz N, Becker M (1984) The health belief model: A decade later. Health Education Quarterly, 11:1-47.

[108] Kara S, Manmek M, Kaebernick H, Ibbotson S (2008) Assessment of products for optimal lifetime CIRP Annals 57/1:1-4.

[109] Kleiminger W, Mattern F, Santini S (2014) Predicting household occupancy for smart heating control: A comparative performance analysis of state-of-the-art approaches. Energy and Buildings 85:493-505.

[110] Klein M, Mogles N, Van Wissen A (2011) Why won't you do what's good for you? Using intelligent support for behavior change. Human Behavior Understanding, Lecture Notes in Computer Science 7065:104-115.

[111] Klöckner CA, Blöbaum A (2010) A comprehensive action determination model: Toward a broader understanding of ecological behaviour using the example of travel mode choice. J Environmental Psychology 30/4:574-586. 
[112] Klöckner CA (2013) A comprehensive model of the psychology of environmental behaviour-A meta-analysis. Global Environmental Change 23/5:1028-1038

[113] Kohtala C (2016) Making "Making" Critical: How Sustainability is Constituted in Fab Lab Ideology. The Design Journal, pp. 1-20.

[114] Kok G, Lo SH, Peters GJY, Ruiter RA (2011) Changing energy-related behavior: An intervention mapping approach. Energy Policy, 39/9:5280-5286.

[115] Kollmuss A, Agyeman J (2002) Mind the gap: Why do people act environmentally and what are the barriers to pro-environmental behavior? Environmental Education Research 8/3:239-260.

[116] Kondoh S, Mishima N, Yoshikawa H (2011) Proposal of cause-effect pattern library for realizing sustainable businesses. CIRP Annals 60/1:33-36.

[117] Kormos C, Gifford R (2014) The validity of self-report measures of proenvironmental behavior: a meta-analytic review. J Environmental Psychology 40:359-371.

[118] Kormos C, Gifford R, Brown E (2015) The Influence of descriptive social norm information on sustainable transportation behavior: A field experiment. Environment and Behavior, 47/5:479-501.

[119] Korosec K (2016) Google's Waze is helping drivers avoid left-hand turns. Fortune magazine 18 June 2016

[120] Krumm J, Brush AB (2011) Learning time-based presence probabilities. Int. Conf. Pervasive Computing. Springer Berlin Heidelberg, pp. 79-96.

[121] Kurisu K (2015) Pro-environmental Behaviors. Springer. SBN: 978-4-43155832-3 (Print) 978-4-431-55834-7(Online)

[122] Kuyer L, Whiteson S, Bakker B, Vlassis N (2008) Multiagent reinforcement learning for urban traffic control using coordination graphs. In Joint European Conf. Machine Learning and Knowledge Discovery in Databases. Springer Berlin Heidelberg, pp. 656-671.

[123] Lai S, Shu LH (2014) Do-it-yourselfers as Lead Users for Environmentally Conscious Behavior. Proc. 21st CIRP Conf. Life Cycle Engineering, Trondheim, Norway, 18-20 June, Procedia CIRP 15/C:431-436.

[124] Latour B (1992) Where are the missing masses? The sociology of a few mundane artifacts, In Shaping technology/Building society (Bijker W.E., Law J. eds.), Cambridge, MA: MIT Press, 225-259.

[125] Lee JD (2006) Human factors and ergonomics in automation design. In G. Salvendy (Ed.) Handbook of Human Factors and Ergonomics. Hoboken, NJ: John Wiley \& Sons, Inc. pp. 1570-1596.

[126] Lee S, Ryu G, Chon Y, Ha R, Cha H (2013) Automatic standby power management using usage profiling and prediction. IEEE Transactions on Human-Machine Systems 43/6:535-46

[127] Leung MC, Norman CF, Lai LL, Chow TT (2012) The use of occupancy space electrical power demand in building cooling load prediction. Energy and Buildings 55:151-163.

[128] Li Q, Meng Q, Cai J, Yoshino H, Mochida A (2009a) Predicting hourly cooling load in the building: a comparison of support vector machine and different artificial neural networks. Energy Conversion and Management 50/1:90-96.

[129] Lilley D, Lofthouse V, Bhamra T (2005) Towards Instinctive sustainable product use. $2^{\text {nd }}$ Int. Conf: Sustainability Creating the Culture, Nov. 2-4, Aberdeen Exhibition \& Conf. Centre, Aberdeen, UK.

[130] Lindenberg S, Steg L (2007) Normative, Gain and Hedonic Goal Frames Guiding Environmental Behavior. J Social Issues 63/1:117-137.

[131] Liu JH, Sibley CG (2004) Attitudes and behavior in social space: Public good interventions based on shared representations and environmental influences. J Environmental Psychology 24/373-384. Doi:10.1016/j.jenvp.2003.12.003

[132] Lockton D, Harrison D, Stanton N (2008) Making the user more efficient: design for sustainable behavior. Int. J Sustainable Engineering 1/1:3-8.

[133] Lockton D, Harrison D, Stanton NA (2010) The Design with Intent method: A design tool for influencing user behavior. Applied Ergonomics, 41/3:382-392.

[134] Lockton D (2012) Attitudes, meaning, emotion and motivation in design for behavior change. Working paper, danlockton.co.uk, last accessed Oct. 13, 2013.

[135] Lockton D, Harrison D, Stanton NA (2012) Models of the user: designers' perspectives on influencing sustainable behavior. J Design Research 10/1-2:7-27.

[136] Lu J, Sookoor T, Srinivasan V, Gao G, Holben B, Stankovic J, Field E, Whitehouse $\mathrm{K}$ (2010) The smart thermostat: using occupancy sensors to save energy in homes. Proc. $8^{\text {th }}$ ACM Conf. Embedded Networked Sensor Systems, pp. 211-224.

[137] Maier J, Fadel G, (2009) Affordance Based Design: A Relational Theory for Design. Research in Engineering Design 20/1:13-27.

[138] Mamidi S, Chang YH, Maheswaran R (2012) Improving building energy efficiency with a network of sensing, learning and prediction agents. Proc. $11^{\text {th }}$ Int. Conf. Autonomous Agents and Multiagent Systems-Vol. 1, pp. 45-52.

[139] McCalley L, Midden C (2002) Energy conservation through product-integrated feedback: The roles of goal-setting and social orientation. J Economic Psychology 23:589-603.

[140] McFarland M (2014) The case for almost never turning left while driving. Washington Post. 9 April 2014

[141] McGrane S (2012) An effort to bury a throwaway culture one repair at a time. New York Times, May 9.

[142] Meyer GG, Främling K, Holmström J (2009) Intelligent products: a survey. Computers in industry 60/3:137-148

[143] Meier A, Aragon C, Hurwitz B, Mujumdar D, Peffer T, Perry D, Pritoni M (2010) How People Actually Use Thermostats, Proc. ACEEE Summer Study on Energy Efficiency in Buildings, pp. 193-206.

[144] Meier H, Roy R, Seliger G (2010) Industrial product-service systems IPS22. CIRP Annals 59/2:607-627.
[145] Midden CJH, Kaiser FG, McCalley LT (2007) Technology's Four Roles in Understanding Individuals' Conservation of Natural Resources. J Social Issues 63/1:155-174

[146] Milfont TL (2012) Cultural differences in environmental engagement. The Oxford Handbook of Environmental and Conservation Psychology, Ed: SD Clayton. Oxford University Press.

[147] Milfont TL, Duckitt J, Cameron LD (2006) A cross-cultural study of environmental motive concerns and their implications for proenvironmental behavior. Environment and Behavior 38/6:745-767.

[148] Momoh DA (2011) Environmentally Significant Behavior of Adopting Warm Energy Conserving Temperatures in Offices: Identifying and Overcoming the Obstacle of Thermal Comfort through Direct Cooling. M.Eng. Thesis, Mechanical and Industrial Engineering, University of Toronto.

[149] Monostori L (2003) AI and machine learning techniques for managing complexity, changes and uncertainties in manufacturing. Engineering Applications of Artificial Intelligence 16/4:277-291.

[150] Montazeri S (2013) Design for Behavior Change: The Role of Product Visual Aesthetics. PhD Dissertation, University of Michigan.

[151] Moreno J, Ortúzar ME, Dixon JW (2006) Energy-management system for a hybrid electric vehicle, using ultracapacitors and neural networks. IEEE Transactions on Industrial Electronics 53/2:614-623.

[152] Mozer MC, Vidmar L, Dodier RH (1997) The Neurothermostat: Predictive optimal control of residential heating systems. Advances in Neural Information Processing Systems, pp. 953-959.

[153] Mozer MC (2004) Lessons from an adaptive house. In Smart Environments: Technologies, Protocols and Applications (eds Cook DJ and Das SK), John Wiley \& Sons, Inc. Hoboken, NJ, USA, pp. 271-294.

[154] Müller ME (2004) Can user models be learned at all? Inherent problems in machine learning for user modelling. The Knowledge Engineering Review 19/01:61-88.

[155] Müller P, Kebir N, Stark R, Blessing L (2009) PSS Layer Method - Application to Microenergy Systems. In: Sakao T., Lindahl M. (eds) Introduction to Product/Service-System Design. Springer, London. Pp. 3-30.

[156] Murphey YL, Park J, Chen Z, Kuang ML, Masrur MA, Phillips AM (2012) Intelligent hybrid vehicle power control-Part I: Machine learning of optimal vehicle power. IEEE Transactions on Vehicular Technology 61/8:3519-3530.

[157] Murphey YL, Park J, Kiliaris L, Kuang ML, Masrur MA, Phillips AM, Wang Q 2013) Intelligent hybrid vehicle power control-Part II: Online intelligent energy management. IEEE Transactions on Vehicular Technology 62/1:69-79.

[158] Nadel S (2012) The rebound effect: large or small? American Council for an Energy-Efficient Economy.

[159] Nemoto Y, Uei K, Sato K, Shimomura Y (2015) A context-based requirements analysis method for PSS design. Procedia CIRP 30: 42-47.

[160] Nonaka I, Toyama R, Konno N (2000) SECI, Ba and Leadership: a UniRed Model of Dynamic Knowledge Creation. Long Range Planning. Vol. 33, pp. 5-34.

[161] Norman D (1999) Affordance, Conventions, and Design. Interactions 6/3:38-42.

[162] Noppers EH, Keizer K, Bolderdijk JW, Steg L (2014) The adoption of sustainable innovations: Driven by symbolic and environmental motives. Global Environmental Change 25:52-62.

[163] Nguyen TA, Aiello M (2013) Energy intelligent buildings based on user activity: A survey. Energy and buildings 56:244-257.

[164] Ölander F, Thøgersen J (1995) Understanding of consumer behaviour as a prerequisite for environmental protection. J Consumer Policy18/4: 345-385.

[165] Oliveira DQ de Souza AZ, Delboni LF (2013) Optimal plug-in hybrid electric vehicles recharge in distribution power systems. Electric Power Systems Research 98:77-85.

[166] Osbaldiston R, Schott JP (2012) Environmental sustainability and behavioral science: Meta-Analysis of proenvironmental behavior experiments. Environment and Behavior 44/2:257-299.

[167] Pannell DJ, Marshall GR, Barr N, Curtis A, Vanclay F, Wilkinson R (2006) Understanding and promoting adoption of conservation technologies by rura landholders. Australian J Experimental Agriculture 46/11:1407-1424.

[168] Peffer T, Pritoni M, Meier A, Aragon C, Perry D (2011) How people use thermostats in homes: A review. Building and Environment 43/12:2529-2541.

[169] Personalized Products Emerging from Tailored User Adapting Logic (PERPETUAL): KU Leuven, VUB and Flanders Make research project, https://perpetual.mech.kuleuven.be/

[170] Peschiera G, Taylor JE, Siegel JA (2010) Response-relapse patterns of building occupant electricity consumption following exposure to personal, contextualized and occupant peer network utilization data. Energy and Buildings 42/8:1329-1336.

[171] Phillips BJ, Sego T (2011) The role of identity in disposal. Lessons from mothers' disposal of children's possessions. Marketing Theory, 11/4: 435-454.

[172] Posselt G, Booij P, Thiede S, Fransman J, Driessen B, Hermmann C (2015) 3D thermal climate monitoring in factory buildings. Procedia CIRP 29: 98-103.

[173] Prochaska J, DiClemente C (1984) The Transtheoretical Approach: Crossing the Traditional Boundaries of change. Irwin, Homewood, IL, USA.

[174] Prodhan MA, Whitehouse K (2012) Hot water DJ: saving energy by pre-mixing hot water. Proc. $4^{\text {th }}$ ACM Workshop on Embedded Sensing Systems for EnergyEfficiency in Buildings. ACM, pp. 91-98.

[175] Purarjomandlangrudi A, Ghapanchi AH, Esmalifalak M (2014) A data mining approach for fault diagnosis: An application of anomaly detection algorithm. Measurement 55:343-352.

[176] Rosenstock IM, Strecher VJ, Becker MH (1988) Social learning theory and the health belief model. Health Education \& Behavior, 15(2), (175-183). 
[177] Sakawa M, Ushiro S, Kato K, Ohtsuka K (1999) Cooling load prediction in a district heating and cooling system through simplified robust filter and multilayered neural network. IEEE SMC'99 Conf. Proc. Systems, Man \&Cybernetics, Vol. 3, pp. 995-1000.

[178] Salem B, Rauterberg M (2004) Multiple user profile merging (MUPE): key challenges for environment awareness. In European Symposium on Ambient Intelligence. Springer Berlin Heidelberg, pp. 196-206.

[179] Sandhu JS, Agogino AM, Agogino AK (2004) Wireless sensor networks for commercial lighting control: decision making with multi-agent systems. In AAAI workshop on sensor networks, Vol. 10, pp. 131-140.

[180] Schwartz SH (1977) Normative Influences on Altruism. Advances in Experimental Social Psychology 10: 221-279.

[181] Schwartz SH (1992) Universals in the content and structures of values: Theoretical advances and empirical tests in 20 countries. In M. Zanna (Ed.), Advances in experimental psychology (25:1-65). Orlando, FL: Academic Press.

[182] Schwartz SH (2012) An Overview of the Schwartz Theory of Basic Values. Online Readings in Psychology and Culture, 2(1)

[183] Scott J, Brush AB, Krumm J, Meyers B, Hazas M, Hodges S, Villar N (2011) PreHeat: controlling home heating using occupancy prediction. Proc. 13th Int. Conf. Ubiquitous computing. ACM, pp. 281-290.

[184] Serna-Mansoux L, Popoff A, Millet D (2014) A simplified model to include dynamic product-user interaction in the eco-design process. J Industrial Ecology 18/4:529-544.

[185] Sheridan TB, Verplank WL (1978) Human and computer control of undersea teleoperators. Technical Report, MIT Man-Machine Systems Laboratory, Cambridge, MA, USA.

[186] Shu LH, Srivastava J, Chou A, Lai S (2015) Three methods for identifying novel affordances. Artificial Intelligence for Engineering Design, Analysis and Manufacturing 29:269-

[187] Shove E, Warde A (1998) Inconspicuous consumption: the sociology of consumption and the environment. Lancaster University, www.lancaster.ac.uk/sociology, last accessed Oct. 9, 2014

[188] Si H, Saruwatari S, Minami M, Morikawa H (2010) A ubiquitous power management system to balance energy savings and response time based on device-level usage prediction. J Information Processing 18:147-163.

[189] Singhvi V, Krause A, Guestrin C, Garrett Jr JH, Matthews HS (2005) Intelligent light control using sensor networks. Proc. 3rd Int. Conf. Embedded networked sensor systems. ACM, pp. 218-229.

[190] Son J, Shu LH (2012) Role of Transformation Principles in Enabling Environmentally Significant Behavior, 19th CIRP Int. Conf. Life Cycle Engineering, Berkeley, CA, May 23-25.

[191] Son J, Shu LH (2014) Mechanical Transformation and Environmentally Conscious Behavior, Artificial Intelligence for Engineering Design, Analysis and Manufacturing 28/2:193-203.

[192] Srivastava J (2016) Product Design Theory and Methods for Changing User Behaviour. Ph.D. Thesis, Mechanical \& Industrial Engineering Univ of Toronto.

[193] Srivastava J, Shu LH (2013a) Encouraging Resource-Conscious Behavior Through Product Design: The Principle of Discretization. ASME J Mechanical Design, 135/6:061002.

[194] Srivastava J, Shu LH (2013b) Affordances and Product Design to Support Environmentally Conscious Behavior. ASME J Mechanical Design, 135/10:101006.

[195] Srivastava J, Shu LH (2014a) An ontology for unifying behavior-change literature. CIRP Annals 63/1:173-176.

[196] Srivastava J, Shu LH (2014b) The Affordance of Absence. Proc. ASME Int. Design Engineering Technical Conf. Aug 17-20, Buffalo, NY, DETC2014-35285.

[197] Srivastava J, Shu LH (2015) Considering Different Motivations in Design for Consumer-Behavior Change. Proc. ASME Int. Design Engineering Technical Conferences, Aug. 2-5, 2015, Boston, MA, DETC2015-47625.

[198] Stark R, Pförtner A (2015) Integrating ontology into PLM-tools to improve sustainable product development. CIRP Annals 64/1:157-160.

[199] Steg L (2005). Car use: lust and must. Instrumental, symbolic and affective motives for car use. Transportation Research A 39:147-162.

[200] Steg L, Bolderdijk JW, Keizer K, Perlaviciute G (2014) An integrated framework for encouraging pro-environmental behavior: The role of values, situational factors and goals. J Environmental Psychology 38:104-115.

[201] Steg L, Perlaviciute G, van der Werff E, Lurvink J (2014) The significance of hedonic values for environmentally relevant attitudes, preferences, and actions. Environment and Behavior 46/2:163-192.

[202] Steg L, Vlek C (2009) Encouraging pro-environmental behavior: An integrative review and research agenda. J. Environmental Psychology 29/3:309-317.

[203] Stern PC, Dietz T, Abel T, Guagnano GA, Kalof L (1999) A value-belief-norm theory of support for social movements: The case of environmentalism. Human Ecology Review 6/2:81-97.

[204] Stern PC (2000) Towards a coherent theory of environmentally significant behavior. J Social Issues 56/3:407-424.

[205] Sussman R, Gifford R (2012) Please turn off the lights: The effectiveness of visual prompts. Applied ergonomics 43/3:596-603.

[206] Sutherland JW, Richter JS, Hutchins MJ, Dornfeld D, Dzombak R Mangold J, Robinson S, Hauschild MZ, Bonou A, Schönsleben P, Friemann F (2016) The role of manufacturing in affecting the social dimension of sustainability. CIRP Annals 65/2:689-712.

[207] Telenko C, Seepersad C (2014) Scoping usage contexts and scenarios in ecodesign. Proc. Int. Design Engineering Technical Conf. Aug. 17-20, Buffalo, NY, USA, DETC2014-34846.
[208] Thaler RH, Sunstein CR (2008) Nudge: Improving Decisions about Health, Wealth, and Happiness. Penguin Books, New York, NY, USA

[209] Thøgersen J (2009) The motivational roots of norms for environmentally responsible behavior. Basic and Applied Social Psychology 31:348-362.

[210] Thorpe A (2010) Design's role in sustainable consumption. Design Issues 26/2:3-16.

[211] Tominaga S, Shimosaka M, Fukui R, Sato T (2012) A unified framework for modeling and predicting going-out behavior. Pervasive Computing. Springer Berlin Heidelberg, pp. 73-90.

[212] Tomiyama T, Yoshikawa H (1985) Extended General Design Theory, in Design Theory for CAD, Proc. IFIP WG 5.2 Working Conf., Tokyo, (Eds: H Yoshikawa \& E A. Warman), North Holland, Amsterdam, pp. 95-130.

[213] Toner K, Gan M, Leary MR (2014) The impact of individual and group feedback on environmental intentions and self-beliefs. Environment and Behavior 46/1:24-45.

[214] Townsend AM (2013) Smart cities: Big data, civic hackers, and the quest for a new utopia. WW Norton \& Company.

[215] Trasarti R, Pinelli F, Nanni M, Giannotti F (2011) Mining mobility user profiles for car pooling. Proc. 17th ACM SIGKDD Int. Conf. Knowledge discovery and data mining. ACM, pp. 1190-1198.

[216] Triandis HC (1977) Interpersonal behavior. Monterey, CA: Brooks/ Cole.

[217] Tromp N, Hekkert P, Verbeek PP (2011) Design for socially responsible behavior: a classification of influence based on intended user experience, Design Issues 27/3:3-19.

[218] Truong NC, McInerney J, Tran-Thanh L, Costanza E, Ramchurn SD (2013) Forecasting multi-appliance usage for smart home energy management. Proc. 23rd Int. Joint Conf. Artificial Intelligence. AAAI Press.

[219] Tversky A, Kahneman D (1974) Judgment under uncertainty: Heuristics and biases. Science 185:1124-1131.

[220] Ueda K, Takenaka T, Vancza J, Monostori L (2009) Value creation and decision-making in sustainable society, CIRP Annals 58/2:681-700.

[221] Uiterkamp AJMS, Vlek C (2007) Practice and outcomes of multidisciplinary research for environmental sustainability. J Social Issues 63/1:175-197.

[222] Uschold M, Gruninger M (1996) Ontologies: Principles, Methods and Applications, Knowledge Engineering Review 11/2. 93-136.

[223] Vázquez FI, Kastner W (2010) Usage profiles for sustainable buildings. IEEE Conf. Emerging Technologies and Factory Automation. IEEE, pp. 1-8.

[224] Vázquez FI, Kastner W (2011) Clustering methods for occupancy prediction in smart home control. IEEE Int. Symp. on Industrial Electronics, pp. 1321-1328.

[225] Ventä O (2007) Intelligent products and systems: Technology theme-final report. Technical Report, VTT Technical Research Centre of Finland.

[226] Verbeek PP (2006) Materializing morality design ethics and technological mediation. Science, Technology and Human Values 31/3:361-380.

[227] Vicente KJ (2006) The Human Factor: Revolutionizing the Way People Life with Technology. New York. Routledge, 2006.

[228] von Hippel E (1986) Lead users: A source of novel product concepts. Management Science 32(7):791-805.

[229] Westkaemper E, Alting L, Arndt G (2000) Life Cycle management and assessment: Approaches and visions towards sustainable manufacturing. CIRP Annals 49/2:501-526.

[230] Wever R, van Kuijk J, Boks C (2008) User-centred design for sustainable behavior. Int. J Sustainable Engineer 1/1:9-20.

[231] Whitmarsh L (2009) Behavioral responses to climate change: Asymmetry of intentions and impacts. J Environmental Psychology 29/13-23.

[232] Wilson GT, Lilley D, Bhamra TA (2013) Design feedback interventions for household energy consumption reduction,16th Conf. European Roundtable Sustainable Consumption and Production \& 7th Conf. Environmental Management for Sustainable Universities, Istanbul, Turkey, 4-7 June.

[233] Withanage C, Ashok R, Hölttä-Otto K, Otto K (2014) Identifying and Categorizing Opportunities for Design for Sustainable User Behavior. Proc. Int. Design Engineering Tech. Conf. Aug. 17-20 Buffalo, NY, USA, DETC2014-34798.

[234] Wong JKW, Li H, Wang SW (2005) Intelligent building research: a review. Automation in construction 14/1:143-159.

[235] Woodruff A, Mankoff J (2009) Environmental sustainability. IEEE Pervasive Computing 1:18-21.

[236] Yan K, Shen W, Mulumba T, Afshari A (2014) ARX model based fault detection and diagnosis for chillers using support vector machines. Energy and Buildings 81:287-295.

[237] Yang R, Newman MW (2013) Learning from a learning thermostat: lessons for intelligent systems for the home. Proc. Int. Joint Conf. Pervasive and Ubiquitous Computing. ACM, pp. 93-102.

[238] Yao Y, Lian Z, Liu S, Hou Z (2004) Hourly cooling load prediction by a combined forecasting model based on analytic hierarchy process. Int. J Thermal Sciences 43/11:1107-1118.

[239] Yim H, Herrmann C (2003) Consumer behavior on ecoproduct: Why consumers do not buy an ecoproduct. Proc. EcoDesign2003: 3rd Int. Symp. Env. Conscious Design \& Inverse Manufg. Tokyo, Japan, Dec. 8-11. Pp. 771-778.

[240] Yoshikawa H (1981) General design theory and a CAD system, Man-machine Communication in CAD/CAM (eds. T Sata. \& EA Warman), pp. 35-58.

[241] Yu Y, Woradechjumroen D, Yu D (2014) A review of fault detection and diagnosis methodologies on air-handling units. Energy \& Buildings 82:550-562.

[242] Zachrisson J, Boks C (2010) When to apply different design for sustainable behavior strategies? Proc. ERSCP-EMSU, Oct. 25-29, Delft, The Netherlands.

[243] Zhao Y, Thurston D (2013) Maximizing profits from end-of-life and initial sales with heterogeneous demand. ASME J Mechanical Design, 135/4:041001-10. 